\title{
Review on the Relationship Between Liquid Aerospace Fuel Composition and Their Physicochemical Properties
}

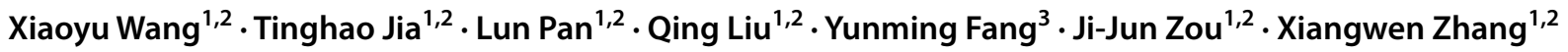

Received: 26 August 2020 / Revised: 8 September 2020 / Accepted: 12 September 2020 / Published online: 21 November 2020

(c) The Author(s) 2020

\begin{abstract}
The development of advanced air transportation has raised new demands for high-performance liquid hydrocarbon fuels. However, the measurement of fuel properties is time-consuming, cost-intensive, and limited to the operating conditions. The physicochemical properties of aerospace fuels are directly influenced by chemical composition. Thus, a thorough investigation should be conducted on the inherent relationship between fuel properties and composition for the design and synthesis of high-grade fuels and the prediction of fuel properties in the future. This work summarized the effects of fuel composition and hydrocarbon molecular structure on the fuel physicochemical properties, including density, net heat of combustion (NHOC), low-temperature fluidity (viscosity and freezing point), flash point, and thermal-oxidative stability. Several correlations and predictions of fuel properties from chemical composition were reviewed. Additionally, we correlated the fuel properties with hydrogen/carbon molar ratios $\left(n_{\mathrm{H} / \mathrm{C}}\right)$ and molecular weight $(M)$. The results from the least-square method implicate that the coupling of $\mathrm{H} / \mathrm{C}$ molar ratio and $M$ is suitable for the estimation of density, NHOC, viscosity and effectiveness for the design, manufacture, and evaluation of aviation hydrocarbon fuels.
\end{abstract}

Keywords Liquid hydrocarbon fuel $\cdot$ Physicochemical properties $\cdot$ Composition $\cdot$ Molecular structure $\cdot$ Fuel properties correlation

Electronic supplementary material The online version of this article (https://doi.org/10.1007/s12209-020-00273-5) contains supplementary material, which is available to authorized users.

$\triangle$ Lun Pan

panlun76@tju.edu.cn

$\triangle$ Yunming Fang

fangym@mail.buct.edu.cn

$\triangle$ Ji-Jun Zou

jj_zou@tju.edu.cn

1 Key Laboratory for Green Chemical Technology of the Ministry of Education, School of Chemical Engineering and Technology, Tianjin University, Tianjin 300072, China

2 Collaborative Innovative Center of Chemical Science and Engineering (Tianjin), Tianjin 300072, China

3 Department of Chemical Engineering, National Energy R\&D Research Center for Biorefinery, Beijing University of Chemical Technology, Beijing 100029, China

\section{Introduction}

Liquid hydrocarbon fuels are the dominant energy source in global air transportation, and they have developed rapidly in recent years. However, the sustained and steadily growing demand for air transportation has resulted in the increased aviation fuel consumption, which propels the diversified development of new alternative fuels from non-petroleum resources, e.g., oil sands, oil shale, coal, natural/shale gas, biomass, etc. [1]. Meanwhile, such development also presents new challenges to the performance of liquid hydrocarbon fuels. From a long-term and strategic perspective, the fundamental properties of hydrocarbon fuels should be further evaluated and improved to meet severe requirements. The difference in the physicochemical properties of aviation fuels should be attributed to their varied chemical composition [2]. Thus, the relationship between the chemical composition and properties of hydrocarbon fuels must be understood to support the development of new alternative fuels and enhance the properties of current aviation fuels.

Prior to being used, the physicochemical properties of aviation fuels, such as the density, net heat of combustion 
(NHOC), low-temperature fluidity, flash point, and thermaloxidative stability, should be comprehensively evaluated. However, the measurement of fuel properties is time-consuming, cost-intensive, and limited to the operating conditions [3]. By contrast, fuel properties can be predicted based on their chemical composition; prediction of chemical composition requires a small amount of fuel sample. The correlations and predictions of fuel properties based on chemical composition have gained important guidance to the design and synthesis of new high-performance jet fuels.

In general, aviation fuels, such as Jet-A, mainly consist of several hydrocarbons with different molecular structures, including n-paraffins, iso-paraffins, cyclo-paraffins, and aromatics (see detailed composition in Fig. 1), coupled with trace amounts of oxygenates, olefins, and additives [4]. Although the composition-property relationship is complex due to the complex composition of fuels, the fundamental properties of aviation fuels can still be predicted based on their fuel composition [3, 5]. Vozka and Kilaz [3] provided composition analysis approaches, i.e., nuclear magnetic resonance (NMR), infrared (IR) spectroscopy, Raman spectroscopy, and gas chromatography (GC), for the prediction of jet fuel properties.

In this work, we summarized the effects of molecular structure on hydrocarbon properties and the relationship between the chemical composition and properties (including density, NHOC, low-temperature fluidity (viscosity and freezing point), flash point, and thermal-oxidative stability) of aviation fuels (Fig. 2). Additionally, we correlated the fuel properties with hydrogen/carbon molar ratios $\left(n_{\mathrm{H} / \mathrm{C}}\right)$ and molecular weight $(M)$. The results will be helpful for the

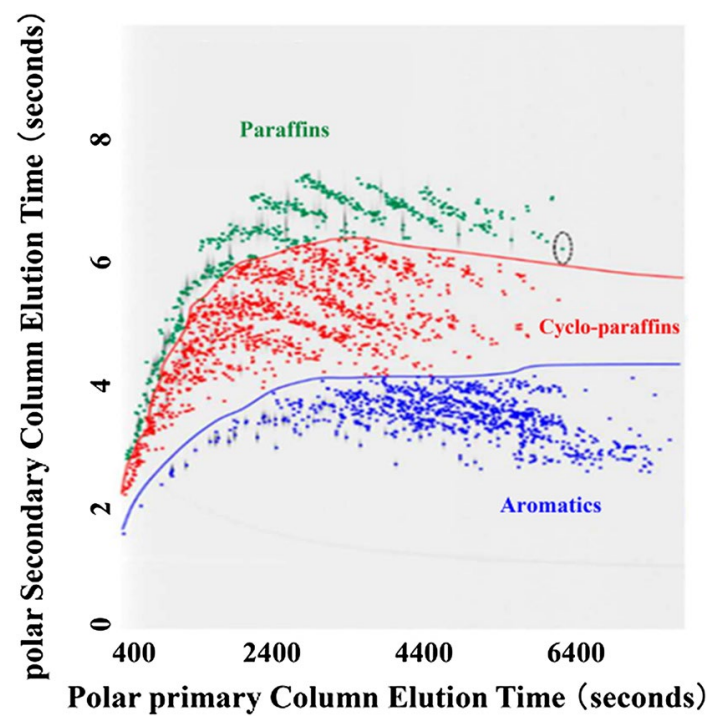

Fig. 1 GC $\times$ GC image of Jet-A (reproduced with the permission from Ref .[6])

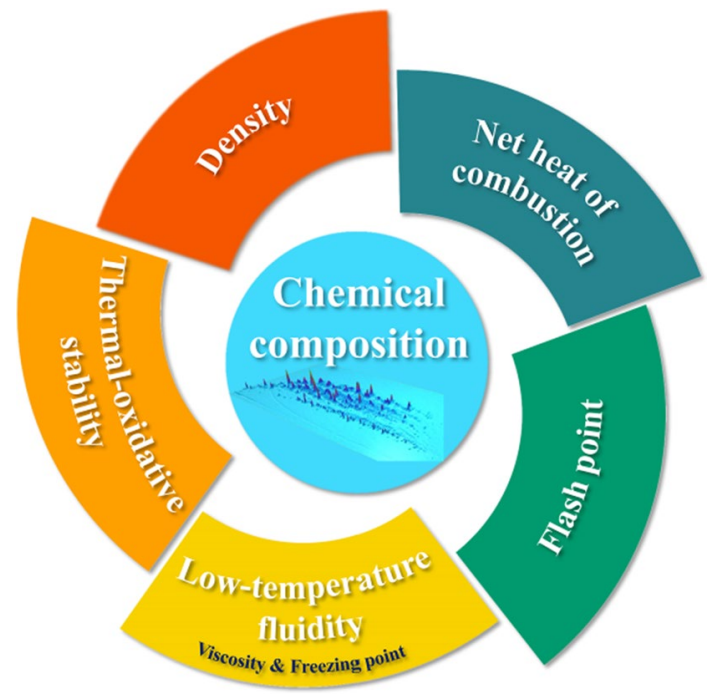

Fig. 2 Correlation between the chemical composition and physicochemical properties of hydrocarbon fuels

design, manufacture, and evaluation of new aviation hydrocarbon fuels.

\section{Density}

\section{Relationship Between Density and Fuel Composition}

Density is a basic aviation fuel property that can influence the loaded fuel weight and aircraft range, which are important for the capacity of aircrafts, especially volume-limited vehicles [7]. Density is also useful in the flow rate calculation and the design of fuel metering system and fuel tank [8]. For aviation turbine fuels, the density is required to be $0.775-0.800 \mathrm{~g} / \mathrm{cm}^{3}$ at $15{ }^{\circ} \mathrm{C}$ (ASTM D7566-18 [9] and D1655-18 [10]).

Chemical composition determines the density of hydrocarbon fuel. In general, the density of hydrocarbon fuels decreases in the order of aromatics $>$ cyclo-paraffins $>$ paraffins with the same number of carbon atoms, i.e., hydrocarbon fuels with a low $\mathrm{H} / \mathrm{C}$ molar ratio have a high density. The density of kerosene fractions decreases linearly with the increase in paraffin content (Fig. 3a) [11]. n-Paraffins are generally denser than iso-paraffins because the branching chains can limit the molecular aggregation of hydrocarbons [12].

Fuel density can be promoted by increasing the cycloparaffin content. Elmalik et al. [4] observed that the density of the hydrocarbon blend composed of n-, iso-, and cyclo-paraffins showed a linear growth with the increase in cyclo-paraffin content (Fig. 3b). Cyclo-paraffins with cis configuration typically possess a higher density than 

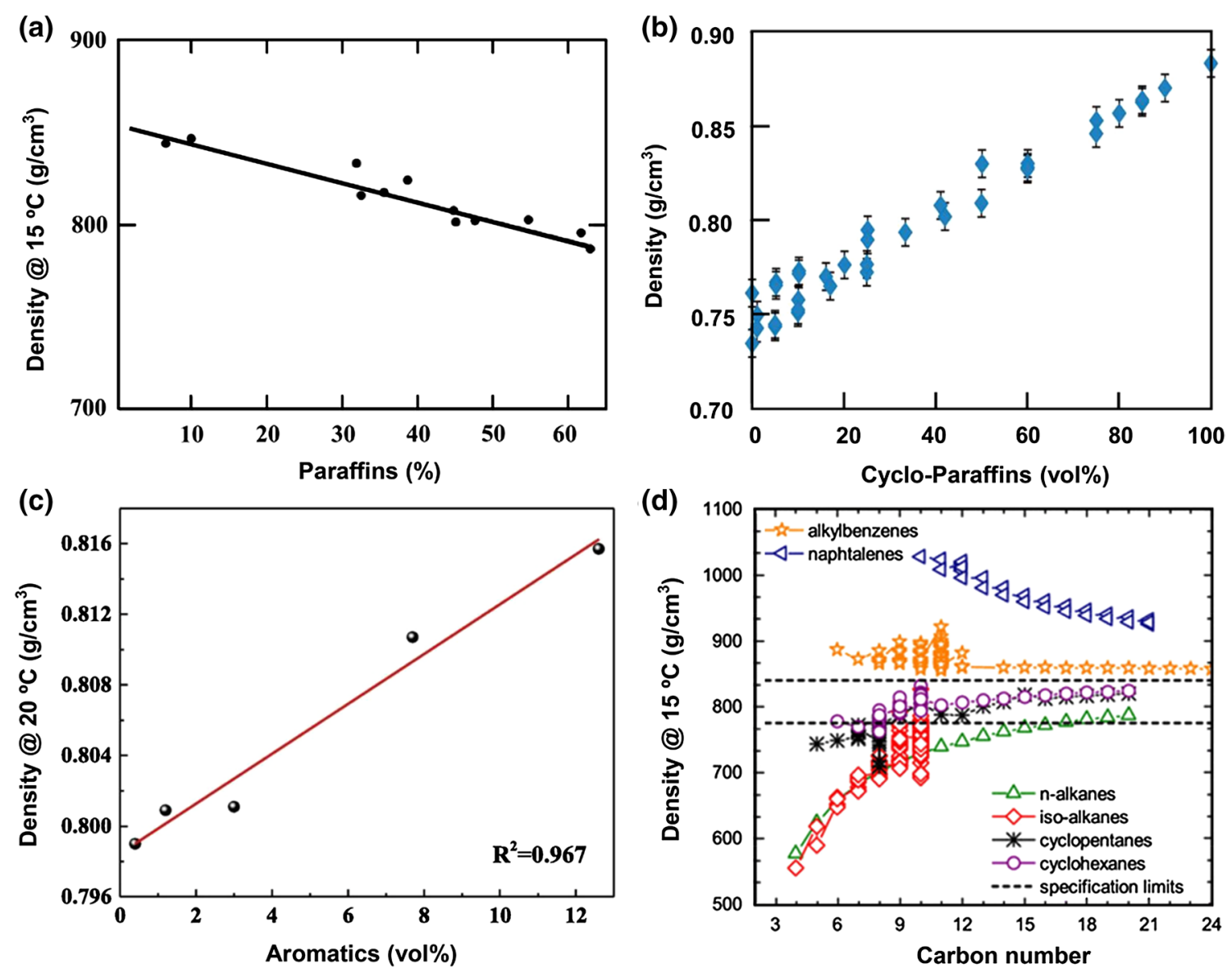

Fig. 3 Fuel density versus a paraffin content of kerosene fractions (reproduced with permission from Ref. [11]), b cyclo-paraffin content of hydrocarbon blends composed of n-, iso-, and cyclo-paraffins (reproduced with permission from Ref. [4]), $\mathbf{c}$ total aromatic mass

content of RP-3 jet fuels with different hydrogenation degrees (reproduced with permission from Ref. [16]), and $\mathbf{d}$ the carbon number of several classes of hydrocarbons (reproduced with permission from Ref. [1])

their trans configurations (symmetry structure) because of the twisted structure of cis configuration, e.g., cis-decalin $\left(0.897 \mathrm{~g} / \mathrm{cm}^{3}\right)$ versus trans-decalin $\left(0.870 \mathrm{~g} / \mathrm{cm}^{3}\right)$ [13]. For alkyl-substituted cyclo-paraffins, such as methylcyclohexane $\left(0.765 \mathrm{~g} / \mathrm{cm}^{3}\right)$, butylcyclohexane $\left(0.796 \mathrm{~g} / \mathrm{cm}^{3}\right)$ [14], and 1,2dimethylcyclohexane $\left(0.796 \mathrm{~g} / \mathrm{cm}^{3}\right)$ [15], the increased chain length of the alkyl substituent and alkyl substituent number can slightly increase the density. Moreover, the position of alkyl substituents affects the fuel density. Ortho-substituted cyclo-paraffins usually have a higher density compared with meta- and para-substituted cyclo-paraffins due to more compact molecules of the former, e.g., cis-1,2-dimethylcyclohexane $\left(0.796 \mathrm{~g} / \mathrm{cm}^{3}\right)$ versus cis-1,4-dimethylcyclohexane $\left(0.783 \mathrm{~g} / \mathrm{cm}^{3}\right)$ [15].

Aromatics possess a higher density than paraffins and cyclo-paraffins, and increasing the aromatic content can increase the fuel density [8]. Jia et al. [16] observed that the densities of RP-3 jet fuels with different hydrogenation degrees decreased linearly with the decline in the aromatic content because hydrogenation converted the aromatics into

cyclo-paraffins (Fig. 3c). Similar to alkyl-substituted cycloparaffins, alkyl substituents in the aromatic ring influence the aromatic density. The decreased distance between alkyl substituents can improve the density of alkyl-substituted aromatic; thus, the density of ortho-substituted aromatic is higher than that of meta- and para-substituted aromatic, e.g., $o$-xylene $\left(0.875 \mathrm{~g} / \mathrm{cm}^{3}\right)$ versus $p$-xylene $\left(0.857 \mathrm{~g} / \mathrm{cm}^{3}\right)$ [17].

Meanwhile, the number of total carbon atoms can also influence the fuel density. As shown in Fig. 3d, the increase in the total carbon number of most hydrocarbons, except alkylbenzene and naphthalene, leads to a high density [1]. The density of alkylbenzene remains almost constant, whereas that of naphthalene declines with the increase in carbon number.

Table 1 compares the density of different hydrocarbon fuels. The relatively high density of RG-1 is possibly due to the high concentration of cyclo-paraffins. Similarly, on account of the high aromatic and cyclo-paraffin contents, JP-8, Jet A, and Jet A-1 possess higher density than JP-4 [18]. Compared with conventional jet fuels, most 


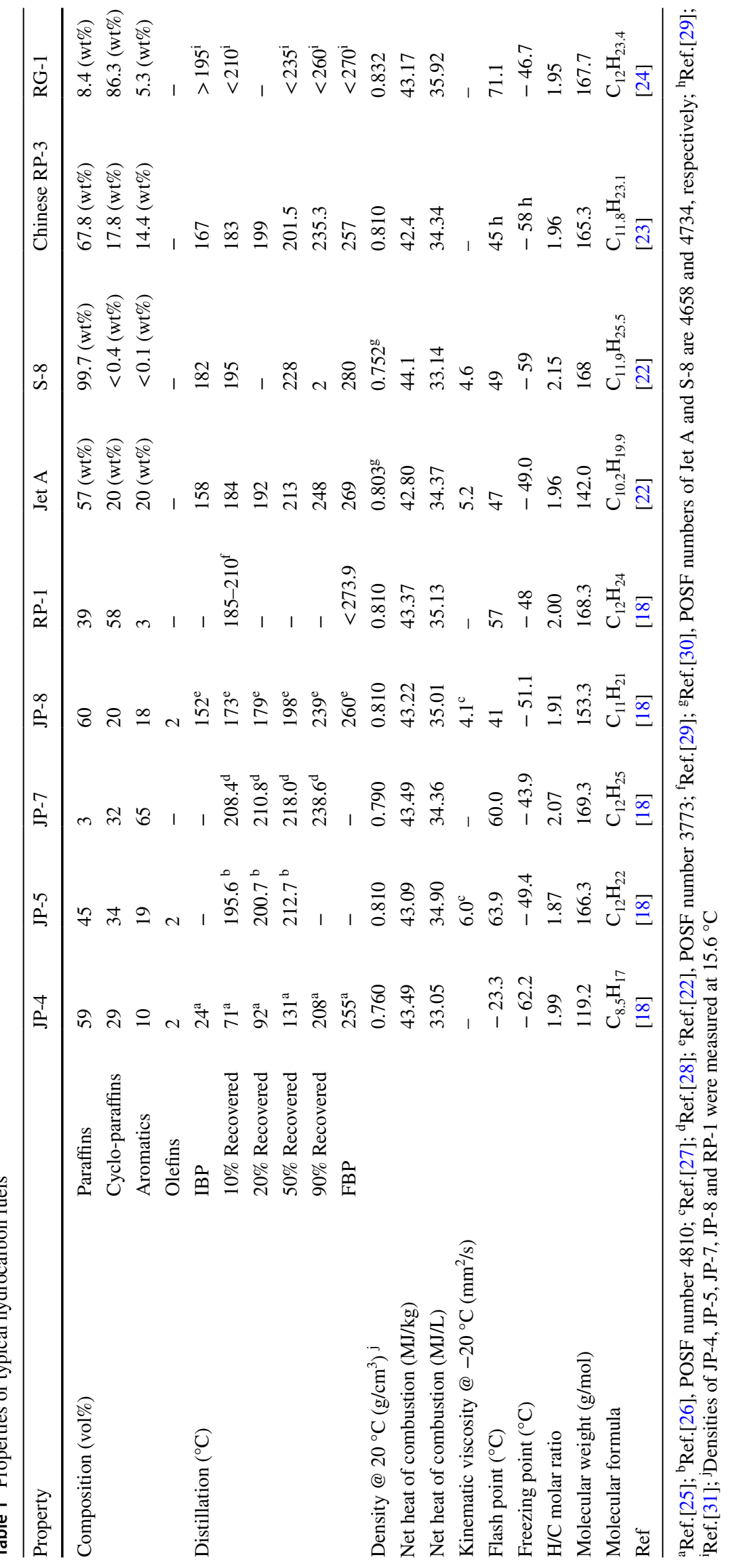


alternative jet fuels usually have a lower density due to their lower content of aromatics [5]. For instance, the densities of Fischer-Tropsch hydroprocessed synthesized paraffinic kerosene (FT-SPK) and hydroprocessed esters and fatty acids (HEFAs) with less than $0.5 \mathrm{wt} \%$ of aromatics possess the density of $0.730-0.770 \mathrm{~g} / \mathrm{cm}^{3}$, whereas the addition of $20 \mathrm{vol} \%$ aromatics to FT-SPK can increase the density to $0.800 \mathrm{~g} / \mathrm{cm}^{3}$ according to ASTM D7566-18 [9]. Al-Nuaimi et al. [19] used aromatic compounds as additives to improve the GTL SPK density. Although aromatics can increase the fuel density, aviation fuels with a high aromatic content can exhibit decreased ignition tendency, low resistance to extinction [20], and increased soot formation and emissions [21]. Hence, ASTM D7566-18 specifies a maximum aromatic volume content of $25.0 \%$ and a minimum content of $8.0 \%$ to ensure adequate lubricity [9].

Hydrocarbons with a multi-ring molecular structure possess a high density, which is essential for high-density fuels [32]. Therefore, efforts have been exerted to synthesize high-density fuels that have a multiple-ring structure, such as RJ-4 $\left(0.94 \mathrm{~g} / \mathrm{cm}^{3}\right)$, a mixture of exo- and endo-tetrahydrodimethylcyclopentadiene synthesized by hydrogenation of dimethylcyclopentadiene, and JP-10 $\left(0.936 \mathrm{~g} / \mathrm{cm}^{3}\right)$ that is an almost pure component of exotetrahydrodicyclopentadiene synthesized by hydrogenation of endo-dicyclopentadiene (endo-DCPD) and catalytic isomerization [32-34]. Spiro-hydrocarbon fuels with additional rings can exhibit increased density; a high density of $0.952 \mathrm{~g} / \mathrm{cm}^{3}$ was reported for spiro[cyclopentane-1,2'norbornane] $\left(\mathrm{C}_{11} \mathrm{H}_{18}\right)$ synthesized by the zeolite catalytic Mannich-Diels-Alder reaction of biomass and petroleumderived feedstocks [35], whereas the density of spiro[4,5] decane $\left(\mathrm{C}_{10} \mathrm{H}_{18}\right)$ can reach $0.870 \mathrm{~g} / \mathrm{cm}^{3}$ [36]. Notably, liquid diamondoid fuels, such as alkyl adamantanes, alkyl diamantanes, and alkyl triamantanes, also present a high density due to their compact internal molecular structure [37-41].

Strained fuels containing three- or four-membered rings also possess high density. A typical strained fuel is quadricyclane (tetracyclo[3.2.0.0 $\left.0^{2,7} \cdot 0^{4,6}\right]$ heptane; QC, $0.983 \mathrm{~g} /$ $\mathrm{cm}^{3}$ ), which contains two three-membered rings and one four-membered ring [42-45]. Moreover, cyclopropanation, which was first reported by Simmons and Smith [46, 47] through the reaction of alkenes with diiodomethane and a zinc-copper couple, is an effective method for the formation of three-membered carbocyclic rings to increase the fuel density. Oh et al. [48] reported that the density of a series of cyclopropane-fused hydrocarbons synthesized by cyclopropanation of norbornene and DCPDs can reach $0.940-1.040 \mathrm{~g} / \mathrm{cm}^{3}$. Therefore, the construction of a multi-ring structure is an important approach to obtain high-density fuels.
Based on the above demonstrations, fuel density is closely related to the molecular structure, total carbon number, and $\mathrm{H} / \mathrm{C}$ molar ratio of fuels.

\section{Correlation and Estimation of Density}

On the account of a hydrocarbon fuel mixture, Eq. (1) gives an effective method to predict the density of a hydrocarbon mixture, showing a linear function of the mass fraction of each component [49].

$\frac{1}{\rho_{\operatorname{mix}}}=\sum_{i=1}^{n} \frac{x_{i}}{\rho_{i}}$

where $\rho_{\text {mix }}$ is the mixture density, and $x_{i}$ and $\rho_{i}$ are the mass fraction and density of $i$ th component, respectively.

\section{Correlation of Density and Composition of Fuels}

Fuel density is generally dependent on the chemical composition. The fuel composition should be first analyzed by several approaches before the correlations of fuel density and the detailed composition are established.

Cookson et al. [50, 51] determined the mass fractions of n-paraffins, cyclo-paraffins combined with iso-paraffins, and aromatics through ${ }^{13} \mathrm{C} \mathrm{NMR}$, high-performance liquid chromatography (HPLC), and GC to establish the linear expressions of composition and fuel density by multi-linear regression (MLR) analysis (Entries 1-4, Table 2). Then, the aromatic carbon and n-alkyl carbon contents were introduced to predict the fuel density (Entries 5-10, Table 2) [52, 53]. Liu et al. [54] determined the detailed composition of 80 jet fuels by GC-mass spectrometry (GC-MS) and categorized the chemical composition into eight hydrocarbon classes. With the help of an artificial neural network (ANN), they presented the multiple linear correlations of composition-property of fuels to predict fuel density (Entries 11-12, Table 2). Furthermore, Shi et al. [55] used two-dimensional $\mathrm{GC}$ with $\mathrm{MS}$ and flame ionization detector $(\mathrm{GC} \times \mathrm{GC}-\mathrm{MS} /$ FID) to accurately measure the aviation fuel composition, which was sorted into 10 hydrocarbon classes and carbon numbers $\left(\mathrm{C}_{7}-\mathrm{C}_{19}\right)$; they further developed the quantitative composition-property relationship of aviation fuels by different statistical algorithms, including weighted average (WA) method, partial least squares (PLS) analysis, genetic algorithm, and modified WA method. Moreover, the PLS regression models based on near-IR or Fourier transform IR spectroscopy (FT-IR) spectra can provide a practical method to predict fuel density [56-58]. Al-Nuaimi et al. [19] predicted the density of hydrocarbon mixture with mass fractions of n-, iso-, and cyclo-paraffins (Entry 13, Table 2). Gülüm et al. [59] proposed one- and two-dimensional regression models to predict the density of fuel blends based 
Table 2 Correlations between density and fuel composition

\begin{tabular}{lll}
\hline Entry & Developed correlative models & References \\
\hline $1^{\mathrm{a}}$ & $1 / \rho\left(\mathrm{g} / \mathrm{cm}^{3}\right)=1.4503 \omega_{\mathrm{n}}+1.1821 \omega_{\mathrm{bc}}+1.0300 \omega_{\mathrm{ar}}$ & {$[50]$} \\
2 & $1 / \rho\left(\mathrm{g} / \mathrm{cm}^{3}\right)=1.4018 \omega_{\mathrm{n}}+1.1920 \omega_{\mathrm{bc}}+1.0531 \omega_{\mathrm{ar}}$ & \\
3 & $1 / \rho\left(\mathrm{g} / \mathrm{cm}^{3}\right)=1.3579 \omega_{\mathrm{n}}+1.1430 \omega_{\mathrm{bc}}+0.9819 \omega_{\mathrm{ar}}$ & \\
4 & $1 / \rho\left(\mathrm{g} / \mathrm{cm}^{3}\right)=1.4335 \omega_{\mathrm{n}}+1.1374 \omega_{\mathrm{bc}}+0.9383 \omega_{\mathrm{ar}}$ & \\
$5^{\mathrm{b}}$ & $1 / \rho\left(\mathrm{g} / \mathrm{cm}^{3}\right)=0.225 C_{\mathrm{n}}-0.131 C_{\mathrm{ar}}+1.178$ \\
6 & $1 / \rho\left(\mathrm{g} / \mathrm{cm}^{3}\right)=0.251 C_{\mathrm{n}}-0.165 C_{\mathrm{ar}}+1.126$ & \\
7 & $\rho\left(\mathrm{g} / \mathrm{cm}^{3}\right)=-0.10 C_{\mathrm{n}}+0.05 C_{\mathrm{ar}}+0.839$ & \\
$8^{\mathrm{c}}$ & $\rho\left(\mathrm{g} / \mathrm{cm}^{3}\right)=-0.1370 C_{\mathrm{n}}+0.0386 C_{\mathrm{ar}}+0.0005 T_{10}+0.0004 T_{90}+0.6577$ \\
9 & $\rho\left(\mathrm{g} / \mathrm{cm}^{3}\right)=-0.1570 C_{\mathrm{n}}+0.0655 C_{\mathrm{ar}}+0.0003 T_{10}+0.0001 T_{90}+0.7652$ \\
10 & $\rho\left(\mathrm{g} / \mathrm{cm}^{3}\right)=-0.1510 C_{\mathrm{n}}+0.0541 C_{\mathrm{ar}}+0.0004 T_{10}+0.0002 T_{90}+0.7208$ \\
$11^{\mathrm{d}}$ & $\rho\left(\mathrm{g} / \mathrm{cm}^{3}\right)=-0.1713 C_{\mathrm{n}}-0.148 C_{\text {iso }}-0.0937 C_{\mathrm{cyclo}}-0.1178 C_{\mathrm{ar}}+0.9473$ \\
12 & $\rho\left(\mathrm{g} / \mathrm{cm}^{3}\right)=-0.0614 C_{\mathrm{n}}-0.0403 C_{\text {iso }}+0.0193 C_{\text {cyclo }}+0.0359 C_{\mathrm{ar}}$
\end{tabular}

${ }^{\mathrm{a}} \omega_{\mathrm{n}}, \omega_{\mathrm{bc}}$, and $\omega_{\mathrm{ar}}$ are the mass fractions of n-paraffins, cyclo-paraffins plus iso-paraffins, and aromatics, respectively. ${ }^{\mathrm{b}} C_{\mathrm{n}}$ and $C_{\mathrm{ar}}$ are the fractions of n-alkyls and aromatic carbons, respectively. ${ }^{\mathrm{c}} T_{10}$ and $T_{90}$ represent the temperatures at which up to $10 \mathrm{wt} \%$ and $90 \mathrm{wt} \%$ hydrocarbon fuels are distilled, respectively. ${ }^{\mathrm{d}} C_{\text {iso }}$ and $C_{\text {cyclo }}$ are the fractions of iso-alkyls and naphthenic carbon, respectively. ${ }^{\mathrm{e}} \omega_{\text {n-p }}, \omega_{\text {iso-p }}$, and $\omega_{\text {cyclo-p }}$ are the mass fractions of n-, iso-, and cyclo-paraffins, respectively. ${ }^{\mathrm{f}} n_{\mathrm{H} / \mathrm{C}}$ and $M$ are the hydrogen-to-carbon molar ratio and molecular weight, respectively on the fuel composition and temperature. To simplify the correlations of composition-property, Yue et al. [60] proposed a unique regression model that correlates the density with $\mathrm{H} / \mathrm{C}$ molar ratios and $M$ of hydrocarbon fuels (Entry 14, Table 2).

\section{Correlation of Density Versus H/C Molar Ratio and $M$}

The saturation degree of hydrocarbon molecular can be reflected by the $\mathrm{H} / \mathrm{C}$ molar ratio. A high $\mathrm{H} / \mathrm{C}$ molar ratio of hydrocarbon implies the decrease in molecular ring structures, especially aromatic ring structures, in aviation fuel [61], which will decrease the fuel density. Moreover, the $M$ is a significant parameter for describing the molecular structure and the total carbon number of hydrocarbons. To simplify the correlation for practical application, we correlated the density data of 64 kinds of fuels, including aviation, synthetic hydrocarbon, alternative, and bio-jet fuels, with their $\mathrm{H} / \mathrm{C}$ molar ratios and $M$ (Table S1, Supporting Information, SI) by the least-square method.

Figure 4 shows the relationship between the density and $n_{\mathrm{H} / \mathrm{C}} / M^{0.19}$ of 64 hydrocarbon fuels, and Eq. (2) gives the linear regression equation for these fuels with a deviation of $6 \%$. The result shows that the individual hydrocarbon fuels strictly follow the same tendency, i.e., the density decreases with the increase in $n_{\mathrm{H} / \mathrm{C}} / M^{0.19}$, and hydrocarbon fuels with

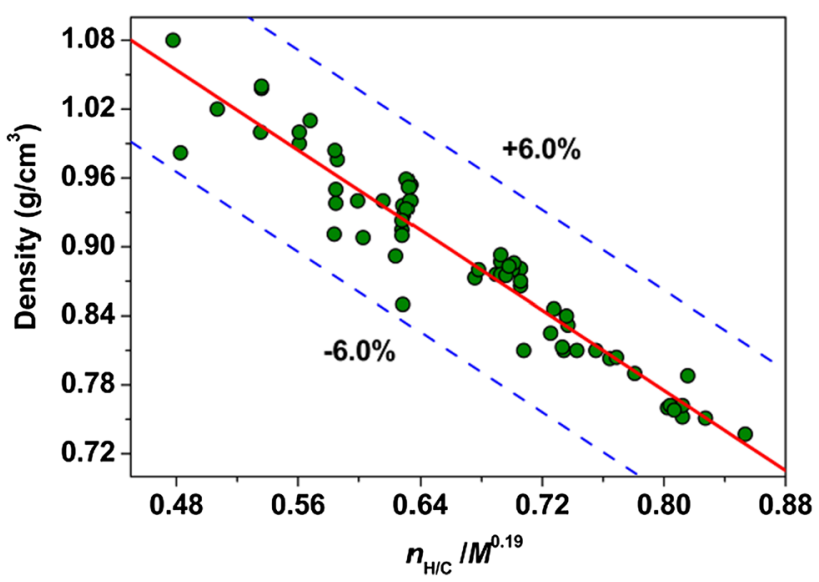

Fig. 4 Densities of 64 hydrocarbon fuels at $20{ }^{\circ} \mathrm{C}$ versus $n_{\mathrm{H} / \mathrm{C}} / M^{0.19}$

the lower $\mathrm{H} / \mathrm{C}$ molar ratio and higher $M$ are prone to possess higher density.

$\rho=1.475 \pm 0.088-0.872 \times n_{\mathrm{H} / \mathrm{C}} / M^{0.19}\left(R^{2}=0.92\right)$

where $\rho$ is the density of hydrocarbon fuels in $\mathrm{g} / \mathrm{cm}^{3}$, and $n_{\mathrm{H} / \mathrm{C}}$ and $M$ are the hydrogen-to-carbon molar ratio and average $M$ of selected hydrocarbon fuels, respectively. 


\section{NHOC}

NHOC is the released energy obtained from the complete combustion of fuel, with products existing in the gaseous state [62]. As an indicator of the energy content of aviation fuels, NHOC directly determines the flying distance and payload of flight and is important for the combustion characteristics, stability, efficiency, and emissions of aviation fuels [63]. The NHOC can be represented by the gravimetric and volumetric NHOC. For most civil aircrafts with a restricted payload weight, the effective payload must be promoted by increasing the gravimetric NHOC. On the contrary, for volume-limited aircraft vehicles, such as rockets and missiles, in which the fuel tank must be designed to be small enough to save sufficient space for the electronic components and electrical equipment, the priority is to increase the volumetric NHOC for maximum flight range [32, 64, 65].

\section{Gravimetric NHOC}

\section{Relationship Between Gravimetric NHOC and Fuel Composition}

The gravimetric NHOC should be higher than $42.8 \mathrm{MJ} / \mathrm{kg}$ for conventional fuels and/or fuel blends to meet ASTM D7566-18 or D1655-18. However, no such restriction exists for synthetic fuels, except the synthesized iso-paraffin fuels with a minimum requirement of $43.5 \mathrm{MJ} / \mathrm{kg}$.

The gravimetric NHOC is positively related to the hydrogen content (H/C molar ratio) of fuels [66-68]; more energy can be released from the complete combustion of hydrogen atoms per unit mass compared with carbon atoms. In general, the gravimetric NHOC of different types of hydrocarbons decreases in the following order: paraffins $>$ cyclo-paraffins $>$ aromatics with the same carbon number (Fig. 5) [1]. The molecular structure of n- and iso-paraffins and the position of alkyl substituents (e.g., 2- and 3-methylalkanes) have a minor effect on the gravimetric NHOC of paraffins due to the same H/C molar ratio. Moreover, the gravimetric NHOC of n-paraffins and iso-paraffins decreases with the increase in the carbon number owing to the reduced $\mathrm{H} / \mathrm{C}$ molar ratio. However, for cyclo-paraffins and alkylbenzenes, the increase in the total carbon number leads to an almost constant and high gravimetric NHOC, respectively [1], because the H/C molar ratio of cyclo-paraffins remains constant, whereas that of the aromatics increases with the rise in carbon atom number.

Conventional jet fuels with high concentration of aromatics and cyclo-paraffins normally exhibit a low

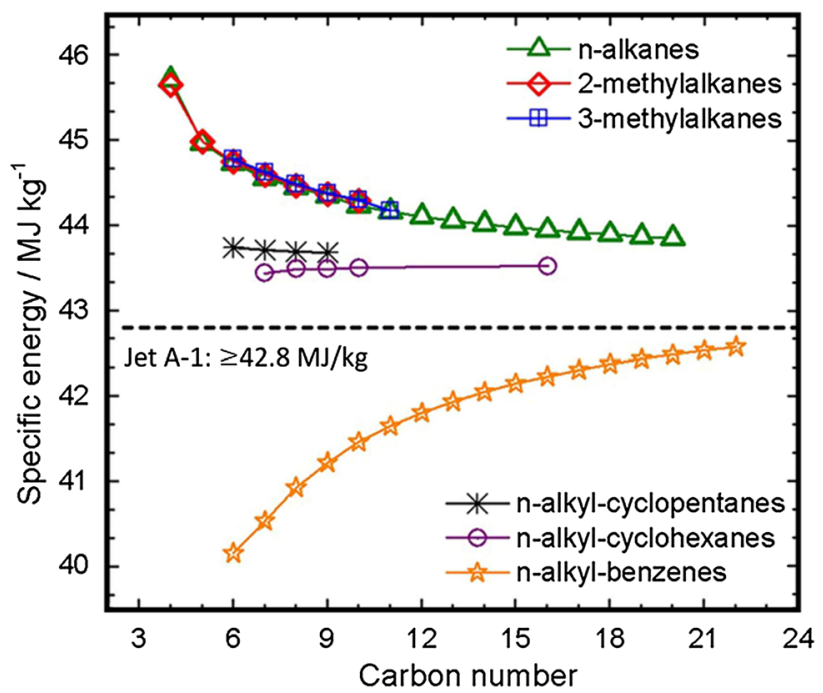

Fig. 5 Gravimetric NHOC versus the total carbon number of hydrocarbons (reproduced with permission from Ref. [1])

gravimetric NHOC [2] because of the low $\mathrm{H} / \mathrm{C}$ ratio caused by the cyclic structure and unsaturated bonds [19]. As shown in Table 1, S-8 with $99.0 \mathrm{wt} \%$ saturated paraffins exhibits a higher gravimetric NHOC (44.1 MJ/ $\mathrm{kg}$ ) than other hydrocarbon fuels containing aromatics. Jia et al. [16] reported that the hydrogenation of Chinese RP-3 jet fuel can increase the gravimetric NHOC, which is negatively related to the aromatic content in linearity, from $43.0 \mathrm{MJ} / \mathrm{kg}$ to $43.2 \mathrm{MJ} / \mathrm{kg}$. In addition, bio-jet fuels possess a higher gravimetric NHOC than conventional jet fuels due to the high concentrations of $\mathrm{n}$ - and iso-paraffins.

The high density of hydrocarbon fuels can be achieved at the cost of reducing the hydrogen content, leading to a low gravimetric NHOC [32]. For example, perhydrofluorene, which contains one five-membered ring and two six-membered rings, has a higher density $(0.959 \mathrm{~g} /$ $\mathrm{cm}^{3}$ ) [69] than decalin $\left(0.881 \mathrm{~g} / \mathrm{cm}^{3}\right)$ [60]; however, its gravimetric NHOC $(41.81 \mathrm{MJ} / \mathrm{kg})$ is lower than that of decalin $(42.59 \mathrm{MJ} / \mathrm{kg})$. Differently, strained hydrocarbon fuels (Table 3) can attain high density and gravimetric NHOC due to the extra strain energy stored in their three- or four-membered rings. The gravimetric NHOC of tricyclo[3.2.1.0 $0^{2,4}$ ]octane $\left(0.94 \mathrm{~g} / \mathrm{cm}^{3}, 41.19 \mathrm{MJ} / \mathrm{kg}\right)$ with a three-membered ring is lower than that of tetracyclo[3.3.1. $\left.0^{2,4} \cdot 0^{6,8}\right]$ nonane $\left(1.00 \mathrm{~g} / \mathrm{cm}^{3}, 43.09 \mathrm{MJ} / \mathrm{kg}\right)$ with two three-membered rings [48], indicating that increasing the number of strained rings leads to increased density and gravimetric NHOC. From Table 3, strained fuels with a strained ring molecular structure and low $\mathrm{H} / \mathrm{C}$ molar ratio exhibit a high gravimetric NHOC, which is contrast to the result for multi-cyclic hydrocarbon fuel. 
Table 3 Obtained properties of several strained hydrocarbons

\begin{tabular}{|c|c|c|c|c|c|c|c|}
\hline Entry & Fuel & Molecular formula & Molecular structure & $\mathrm{H} / \mathrm{C}$ molar ratio & Density $\left(\mathrm{g} / \mathrm{cm}^{3}\right)$ & $\begin{array}{l}\text { Net heat of } \\
\text { combustion } \\
(\mathrm{MJ} / \mathrm{kg})\end{array}$ & References \\
\hline 1. & Quadricyclane & $\mathrm{C}_{7} \mathrm{H}_{8}$ & & 1.14 & 0.892 & 44.350 & {$[45]$} \\
\hline 2. & Tricyclo[3.2.1.0 $\left.0^{2,4}\right]$ octane & $\mathrm{C}_{8} \mathrm{H}_{12}$ & & 1.50 & 0.940 & 41.193 & {$[48]$} \\
\hline 3. & $\begin{array}{l}\text { Tetracyclo }\left[3 \cdot 3 \cdot 1 \cdot 0^{2,4} \cdot 0^{6,8}\right] \\
\text { nonane }\end{array}$ & $\mathrm{C}_{9} \mathrm{H}_{12}$ & & 1.33 & 1.000 & 43.091 & {$[48]$} \\
\hline 4. & $\begin{array}{l}\text { Pentacy- } \\
\left.\text { clo[6.3.1. } 0^{2,7} \cdot 0^{3,5} \cdot 0^{9,11}\right] \\
\text { dodecane }\end{array}$ & $\mathrm{C}_{12} \mathrm{H}_{16}$ & & 1.33 & 1.020 & 42.182 & {$[48]$} \\
\hline 5. & $\begin{array}{l}\text { Tetracyclo }\left[6 \cdot 2 \cdot 1 \cdot 0^{2,7} \cdot 0^{3,5}\right] \\
\text { undecane }\end{array}$ & $\mathrm{C}_{11} \mathrm{H}_{16}$ & & 1.45 & 0.990 & 42.331 & [48] \\
\hline 6. & $\begin{array}{l}\text { Tetracyclo }\left[6 \cdot 2 \cdot 1 \cdot 0^{2,6} \cdot 0^{8,10}\right] \\
\text { undecane }\end{array}$ & $\mathrm{C}_{11} \mathrm{H}_{16}$ & & 1.45 & 1.000 & 42.257 & [48] \\
\hline 7. & Tricyclo $\left[4 \cdot 1 \cdot 0 \cdot 0^{2,4}\right]$ heptane & $\mathrm{C}_{7} \mathrm{H}_{10}$ & & 1.43 & 0.908 & 41.425 & {$[70]$} \\
\hline 8. & Tricyclo[5.2.0.0 2,5$]$ nonane & $\mathrm{C}_{9} \mathrm{H}_{14}$ & & 1.56 & - & 41.319 & {$[70]$} \\
\hline 9. & Tricyclo[3.2.0.0 $\left.0^{2,4}\right]$ heptane & $\mathrm{C}_{7} \mathrm{H}_{10}$ & & 1.43 & - & 42.338 & {$[70]$} \\
\hline 10. & $\begin{array}{l}\text { 4,7,7-Trimethyltricy- } \\
\left.\text { clo[4.1.1. } 0^{2,4}\right] \text { octane }\end{array}$ & $\mathrm{C}_{11} \mathrm{H}_{18}$ & & 1.64 & - & 40.916 & {$[70]$} \\
\hline 11. & $\begin{array}{l}\text { 1,4,4-Trimethyltricy- } \\
\left.\text { clo[5.1.1. } 0^{3,5}\right] \text { octane }\end{array}$ & $\mathrm{C}_{11} \mathrm{H}_{18}$ & & 1.64 & - & 40.901 & {$[70]$} \\
\hline 12. & Dicyclobutyl & $\mathrm{C}_{8} \mathrm{H}_{14}$ & & 1.75 & - & 41.860 & {$[70]$} \\
\hline
\end{tabular}

\section{Correlation and Estimation of Gravimetric NHOC}

The gravimetric NHOC of blended hydrocarbon fuels can be calculated from the NHOC of individual hydrocarbon components using Eq. (3).

$\mathrm{NHOC}=\sum_{i=1}^{n}\left(x_{i} \cdot \mathrm{NHOC}_{i}\right)$

where $\mathrm{NHOC}_{i}$ and $x_{i}$ are the NHOC in $\mathrm{MJ} / \mathrm{kg}$ and mass fraction of $i$ th fuel component, respectively.

ASTM D3338/D3338M-20 [71] and ASTM D4529-17 [72] provide the predicted gravimetric NHOC of hydrocarbon fuels (Entries 1-2, Table 4). Al-Nuaimi et al. [19] calculated the gravimetric NHOC of hydrocarbon mixtures with the mole fractions of n-, iso-, and cyclo-paraffins (Entry 3, Table 4). In view of the strong relationship between NHOC and hydrogen content, Antoine et al. [67] correlated the NHOC with the hydrogen content of different synthetic fuels (Entry 4, Table 4). Analogously, the H/C molar ratio was also used to predict the NHOC of different hydrocarbon fuels (Entry 5, Table 4) [60]. Similar to the prediction of fuel density, HPLC, ${ }^{13} \mathrm{C}$ NMR, FT-IR spectra, GC, GC-MS, and GC $\times$ GC-MS/FID have been conducted to determine the fuel composition. Then, the correlations of gravimetric NHOC with the detailed composition can be established by different regression methods, such as the linear regression method, ANN approaches, and statistical algorithms. Cookson et al. [50-52] used HPLC, GC, and ${ }^{13} \mathrm{C}$ NMR to determine the fuel composition and correlated the gravimetric NHOC with the detailed composition by the linear regression method (Entries 6-10, Table 4). Liu et al. [54] measured the fuel composition by GC-MS and further developed the relationship of composition-gravimetric NHOC by the ANN approach (Entries 11-12, Table 4). Shi et al. [55] determined the aviation fuel composition through 
Table 4 Correlations of gravimetric NHOC with other properties or fuel composition

\begin{tabular}{|c|c|c|}
\hline Entry & Developed correlative models & References \\
\hline $1^{\mathrm{a}}$ & $\begin{aligned} \mathrm{NHOC}(\mathrm{MJ} / \mathrm{kg})= & (5528.73-92.6499 A+10.1601 T+0.314169 A \times T) / D+0.0791707 A \\
& -0.00944893 T-0.000292178 A \times T+35.9936\end{aligned}$ & [71] \\
\hline $2^{\mathrm{b}}$ & $\begin{aligned} \text { NHOC }(\mathrm{MJ} / \mathrm{kg})= & 22.9596-0.0126587 A+26640.9(1 / \rho)+32.622(A / \rho) \\
& -6.69030 \times 10^{-5}(A)^{2}-9217760(1 / \rho)^{2}\end{aligned}$ & {$[72]$} \\
\hline $3^{\mathrm{c}}$ & NHOC $(\mathrm{MJ} / \mathrm{kmol})=0.31094 x_{\mathrm{n}-\mathrm{p}}+0.25465 x_{\text {iso-p }}+0.30892 x_{\text {cyclo-p }}$ & [19] \\
\hline $4^{\mathrm{d}}$ & $\mathrm{NHOC}(\mathrm{MJ} / \mathrm{kg})=0.56566 \times H(\mathrm{wt} \%)+34.885$ & {$[67]$} \\
\hline $5^{\mathrm{e}}$ & NHOC $(\mathrm{MJ} / \mathrm{kg})=4.596 \times n_{\mathrm{H} / \mathrm{C}}+34.197$ & {$[60]$} \\
\hline $6^{\mathrm{f}}$ & NHOC $(\mathrm{MJ} / \mathrm{kg})=44.68 \omega_{\mathrm{n}}+43.26 \omega_{\mathrm{bc}}+40.10 \omega_{\mathrm{ar}}$ & {$[50]$} \\
\hline 7 & NHOC $(\mathrm{MJ} / \mathrm{kg})=44.41 \omega_{\mathrm{n}}+43.33 \omega_{\mathrm{bc}}+40.18 \omega_{\mathrm{ar}}$ & {$[50]$} \\
\hline 8 & NHOC $(\mathrm{MJ} / \mathrm{kg})=44.84 \omega_{\mathrm{n}}+42.93 \omega_{\mathrm{bc}}+39.61 \omega_{\mathrm{ar}}$ & {$[51]$} \\
\hline 9 & NHOC $(\mathrm{MJ} / \mathrm{kg})=45.37 \omega_{\mathrm{n}}+42.88 \omega_{\mathrm{bc}}+39.06 \omega_{\mathrm{ar}}$ & {$[51]$} \\
\hline $10^{\mathrm{g}}$ & $\mathrm{NHOC}(\mathrm{MJ} / \mathrm{kg})=1.50 C_{\mathrm{n}}-2.78 C_{\mathrm{ar}}+42.96$ & {$[52]$} \\
\hline $11^{\mathrm{h}}$ & NHOC $(\mathrm{MJ} / \mathrm{kg})=2.18 C_{\mathrm{n}}+2.04 C_{\text {iso }}+1.07 C_{\text {cyclo }}+0.80 C_{\mathrm{ar}}+41.76$ & [54] \\
\hline $12^{\mathrm{i}}$ & NHOC $(\mathrm{MJ} / \mathrm{kg})=1.36 C_{\mathrm{n}}+1.23 C_{\text {iso }}+0.25 C_{\text {cyclo }}-0.43 C_{\text {ar }}-0.0059 T_{10}-0.0021 T_{90}+44.32$ & {$[54]$} \\
\hline
\end{tabular}

${ }^{\mathrm{a}} A, T$, and $D$ represent the volume fraction of aromatics, the (average) boiling point in ${ }^{\circ} \mathrm{C}$, and the density measured at $15^{\circ} \mathrm{C}$ in $\mathrm{kg} / \mathrm{m}^{3}$ for sulfurfree hydrocarbon fuels, respectively. ${ }^{\mathrm{b}} A$ and $\rho$ represent the aniline point in ${ }^{\circ} \mathrm{C}$ and the density measured at $15^{\circ} \mathrm{C}$ in $\mathrm{kg} / \mathrm{m}^{3}$ for sulfur-free hydrocarbon fuels, respectively. ${ }^{\mathrm{N} H O C}$ is the net heat of combustion of fuel blends in $\mathrm{MJ} / \mathrm{kmol}$, and $x_{\mathrm{n}-\mathrm{p}}, x_{\text {iso-p }}$, and $x_{\text {cyclo-p }}$ are the mole fractions of n-, iso-, and cyclo-paraffins, respectively. ${ }^{\mathrm{d}} H$ represents the mass fraction of hydrogen in hydrocarbon fuels. ${ }^{\mathrm{e}} n_{\mathrm{H} / \mathrm{C}}$ is the hydrogen-to-carbon molar ratio. ${ }^{\mathrm{f}} \omega_{\mathrm{n}}, \omega_{\mathrm{bc}}$, and $\omega_{\mathrm{ar}}$ are the mass fractions of n-paraffins, cyclo-paraffins plus iso-paraffins, and aromatics, respectively. ${ }^{\mathrm{g}} C_{\mathrm{n}}$ and $C_{\mathrm{ar}}$ are the fractions of n-alkyls and aromatic carbons, respectively. ${ }^{\mathrm{h}} C_{\mathrm{iso}}$ and $C_{\text {cyclo }}$ are the fractions of iso-alkyls and naphthenic carbon, respectively. ${ }^{\mathrm{i}} T_{10}$ and $T_{90}$ represent the temperatures at which up to $10 \mathrm{wt} \%$ and $90 \mathrm{wt} \%$ hydrocarbon fuels are distilled, respectively

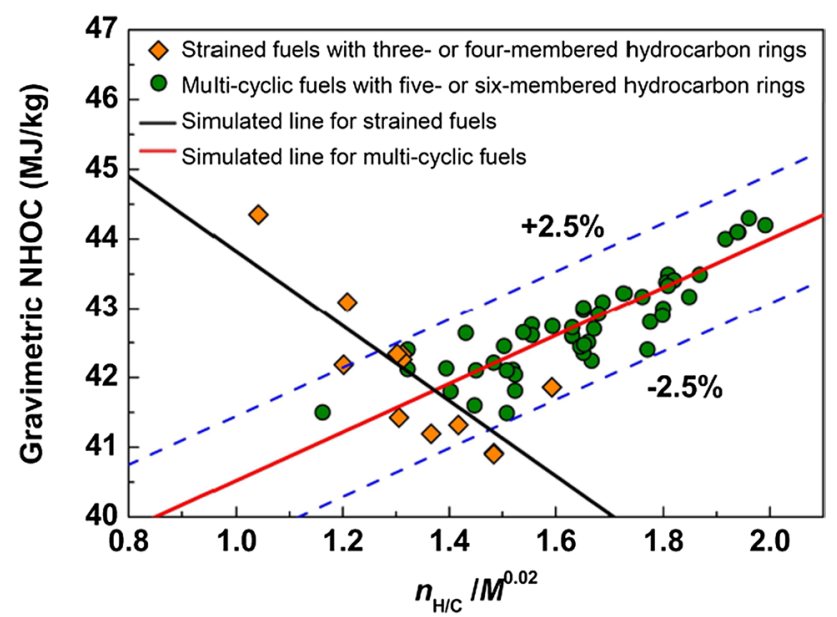

Fig. 6 Gravimetric NHOC of 64 hydrocarbon fuels versus $n_{\mathrm{H} / \mathrm{C}} / M^{0.02}$

GC $\times$ GC-MS/FID and correlated the gravimetric NHOC with the detailed composition by different statistical algorithms. In addition, PLS regression models combined with FT-IR spectra were used for the prediction of the gravimetric NHOC of hydrocarbon fuels [73].

As discussed, the gravimetric NHOC of aviation hydrocarbon fuels is closely related to their hydrogen content. Thus, the H/C molar ratio is an important parameter for the correlation of gravimetric NHOC. Meanwhile, the number of total carbon atoms also affect fuel gravimetric NHOC.
Thus, we correlated the gravimetric NHOC with H/C molar ratios and $M$ of 64 hydrocarbon fuels (Table S1, SI) by the least-square method. As shown in Fig. 6, the correlation can be divided into two different groups: multi-cyclic hydrocarbon fuels containing five- or six-membered rings (red line) and strained hydrocarbon fuels with three- or four-membered rings (black line). For the former group, the relationship between gravimetric NHOC and $n_{\mathrm{H} / \mathrm{C}} / M^{0.02}$ for multi-cyclic hydrocarbon fuels containing five- or six-membered rings can be expressed as Eq. (4).

$\mathrm{NHOC}(\mathrm{MJ} / \mathrm{kg})=37.042 \pm 0.926+3.478 \times n_{\mathrm{H} / \mathrm{C}} / M^{0.02}\left(R^{2}=0.78\right)$

where NHOC is the net heat of combustion per unit mass for hydrocarbon fuel in $\mathrm{MJ} / \mathrm{kg}$ and $n_{\mathrm{H} / \mathrm{C}}$ is the hydrogen to carbon molar ratio.

From Eq. (4), a positively linear correlation exists between the gravimetric NHOC of most multi-cyclic hydrocarbon fuels and $n_{\mathrm{H} / \mathrm{C}} / M^{0.02}$ with an error of $2.5 \%$, which proves that the $\mathrm{H} / \mathrm{C}$ molar ratio determines the gravimetric NHOC for multi-cyclic hydrocarbons.

However, for the strained hydrocarbon fuels with threeor four-membered rings (Table 3), the correlation between gravimetric NHOC and $n_{\mathrm{H} / \mathrm{C}} / M^{0.02}$ exhibits a negatively linear correlation, as described in Eq. (5).

$\mathrm{NHOC}(\mathrm{MJ} / \mathrm{kg})=49.207-5.383 \times n_{\mathrm{H} / \mathrm{C}} / M^{0.02}\left(R^{2}=0.61\right)$ 


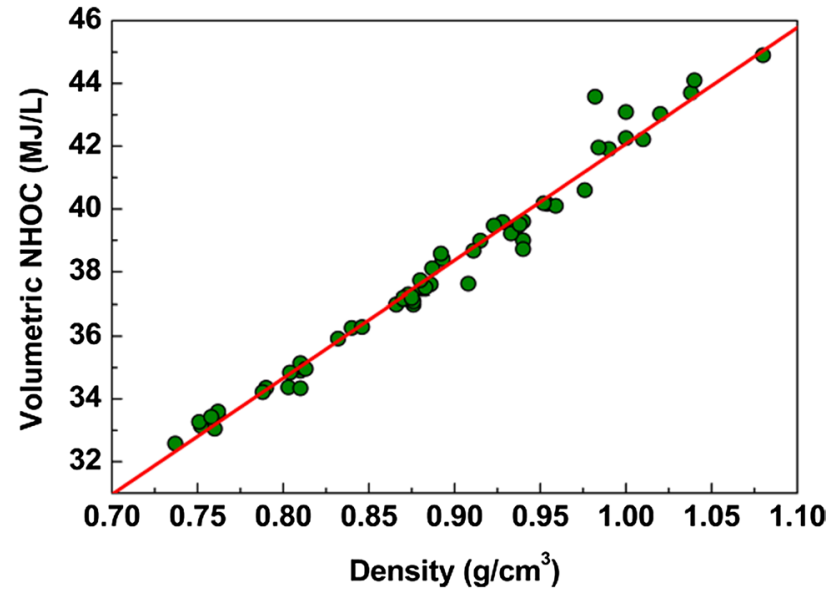

Fig. 7 Volumetric NHOC of 59 kinds of hydrocarbon fuels versus density

Although the increase in three- or four-membered rings reduces the $\mathrm{H} / \mathrm{C}$ molar ratio, the stored strain energy contributes considerable combustion energy to the gravimetric NHOC. Thus, the gravimetric NHOC of strained fuel is negatively related to its $\mathrm{H} / \mathrm{C}$ molar ratio.

\section{Volumetric NHOC}

\section{Correlation Between Volumetric NHOC and Density}

We correlated the volumetric NHOC of 59 hydrocarbon fuels (Table S1, SI) with the fuel density by using the least-square method, and the results are shown in Fig. 7. The volumetric NHOC of hydrocarbon fuels increases linearly with density (with $R^{2}$ of 0.98 , Eq. (6)).

$\mathrm{NHOC}(\mathrm{MJ} / \mathrm{L})=5.01+37.064 \times \rho\left(R^{2}=0.98\right)$

where NHOC and $\rho$ are the volumetric NHOC in MJ/L and density in $\mathrm{g} / \mathrm{cm}^{3}$, respectively.

Given the positively linear correlation between the volumetric NHOC and fuel density, many studies attempted to synthesize high-density fuels to increase the volumetric NHOC and expand the flight distance [32, 35, 36, 69, $74,75]$. A crucial step toward high-density fuels is the synthesis of RJ-4 (39.0 MJ/L) with a density of $0.940 \mathrm{~g} /$ $\mathrm{cm}^{3}$ [34]. As the most widely used missile fuel, JP-10 $\left(0.936 \mathrm{~g} / \mathrm{cm}^{3}\right)$ has a NHOC of $39.40 \mathrm{MJ} / \mathrm{L}$ [33], whereas QC $\left(0.983 \mathrm{~g} / \mathrm{cm}^{3}\right)$, as a strained hydrocarbon fuel, has a higher NHOC (43.58 MJ/L) [45]. RJ-5 (the isomer of dihydrodinorbornadiene, $1.080 \mathrm{~g} / \mathrm{cm}^{3}$ ) is the first aviation hydrocarbon fuel with a NHOC of $44.90 \mathrm{MJ} / \mathrm{L}$; it is synthesized from cycloaddition reactions of norbornadiene, followed by hydrogenation and isomerization [34].
Correlation of Volumetric NHOC Versus H/C Molar Ratio and $M$

Given that the $\mathrm{H} / \mathrm{C}$ molar ratio and $M$ can serve as parameters to determine the fuel density, we correlated the volumetric NHOC with $\mathrm{H} / \mathrm{C}$ molar ratios and $M$ based on 59 hydrocarbon fuels (Table S1, SI); Eq. (7) describes the negative linear equation between the volumetric NHOC of hydrocarbons and $n_{\mathrm{H} / \mathrm{C}} / M^{0.19}$. The result in Fig. 8 shows that the volumetric NHOC decreases linearly with $n_{\mathrm{H} / \mathrm{C}} / M^{0.19}$ with $R^{2}$ of 0.93 . Comparing Figs. 4 and 8 , the density and volumetric NHOC present an excellent linear relationship with $n_{\mathrm{H} / \mathrm{C}} / M^{0.19}$, confirming the positive relationship between the volumetric NHOC and density, consistent with the result in Fig. 7.

$\operatorname{NHOC}(\mathrm{MJ} / \mathrm{L})=60.116 \pm 2.705-33.002 \times n_{\mathrm{H} / \mathrm{C}} / M^{0.19}\left(R^{2}=0.93\right)$

\section{Low-Temperature Fluidity}

Low-temperature fluidity, which can be quantitatively reflected and described by the low-temperature viscosity and freezing point of aviation fuels, is a vital character for the application of fuels, especially in environments with low temperature and high altitudes.

\section{Viscosity}

\section{Relationship Between Viscosity and Fuel Composition}

Viscosity is a fundamental physical property to quantitatively evaluate the fluidity of aviation fuel $[5,76]$ and useful

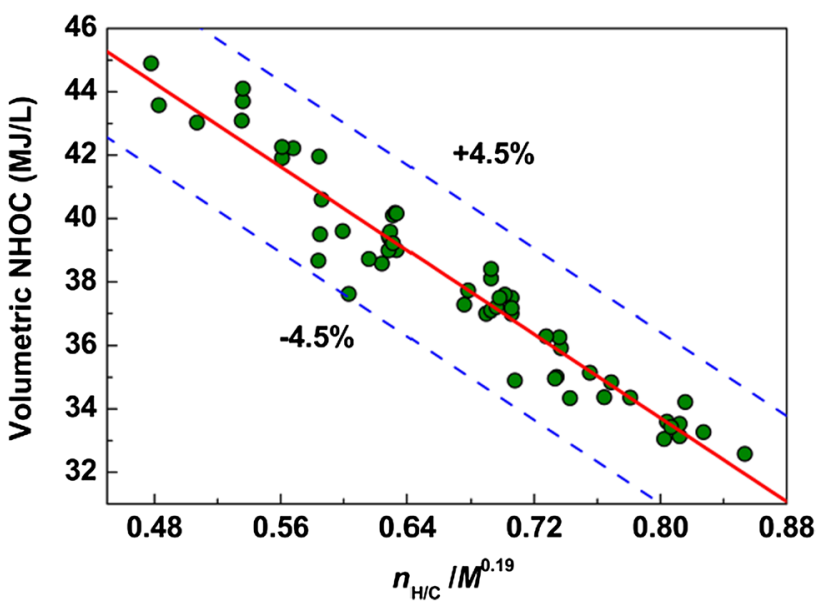

Fig. 8 Volumetric NHOC of 59 hydrocarbon fuels versus $n_{\mathrm{H} / \mathrm{C}} / M^{0.19}$ 
for the calculation of pipeline pressure drop and the design of fuel transfer control system. High-viscosity fuels ultimately result in poor spray atomization, relight difficulties, low-temperature pumping difficulties, and serious operational problems such as engine deposits [65, 76-78]. ASTM D7566-18 specifies that the kinematic viscosity should not exceed $8.00 \mathrm{~mm}^{2} / \mathrm{s}(\mathrm{cst})$ at $-20{ }^{\circ} \mathrm{C}$ for aviation fuels, such as Jet A and Jet A-1. In general, the viscosity of hydrocarbon fuels increases with the $M$ (total carbon number) [76]. As shown in Table 1, the viscosity of JP-5 is $6 \mathrm{~mm}^{2} / \mathrm{s}$ at $-20{ }^{\circ} \mathrm{C}$, which is higher than those of JP-8 $\left(4.10 \mathrm{~mm}^{2} / \mathrm{s}\right)$ and Jet $\mathrm{A}\left(5.20 \mathrm{~mm}^{2} / \mathrm{s}\right)$, due to its higher average $M(166.3 \mathrm{~g} /$ mol). For aliphatic hydrocarbon fuels, the kinematic viscosity increases with the carbon chain length [77].

Cai et al. [79] proposed a quantitative structure-property relationship (QSPR) model to estimate and compare the viscosity (predicted and experimental) of different hydrocarbon class homologs (Fig. 9). The viscosity of n-paraffins, isoparaffins, cyclo-paraffins, olefins, and aromatic homologs increases with the number of carbon atoms at a given temperature. With the same carbon number, cyclo-paraffins and aromatics are more viscous than paraffins $[15,61,76]$. Cyclo-paraffins with cis configuration have a higher viscosity than their trans configuration, e.g., cis-decalin $(2.52$
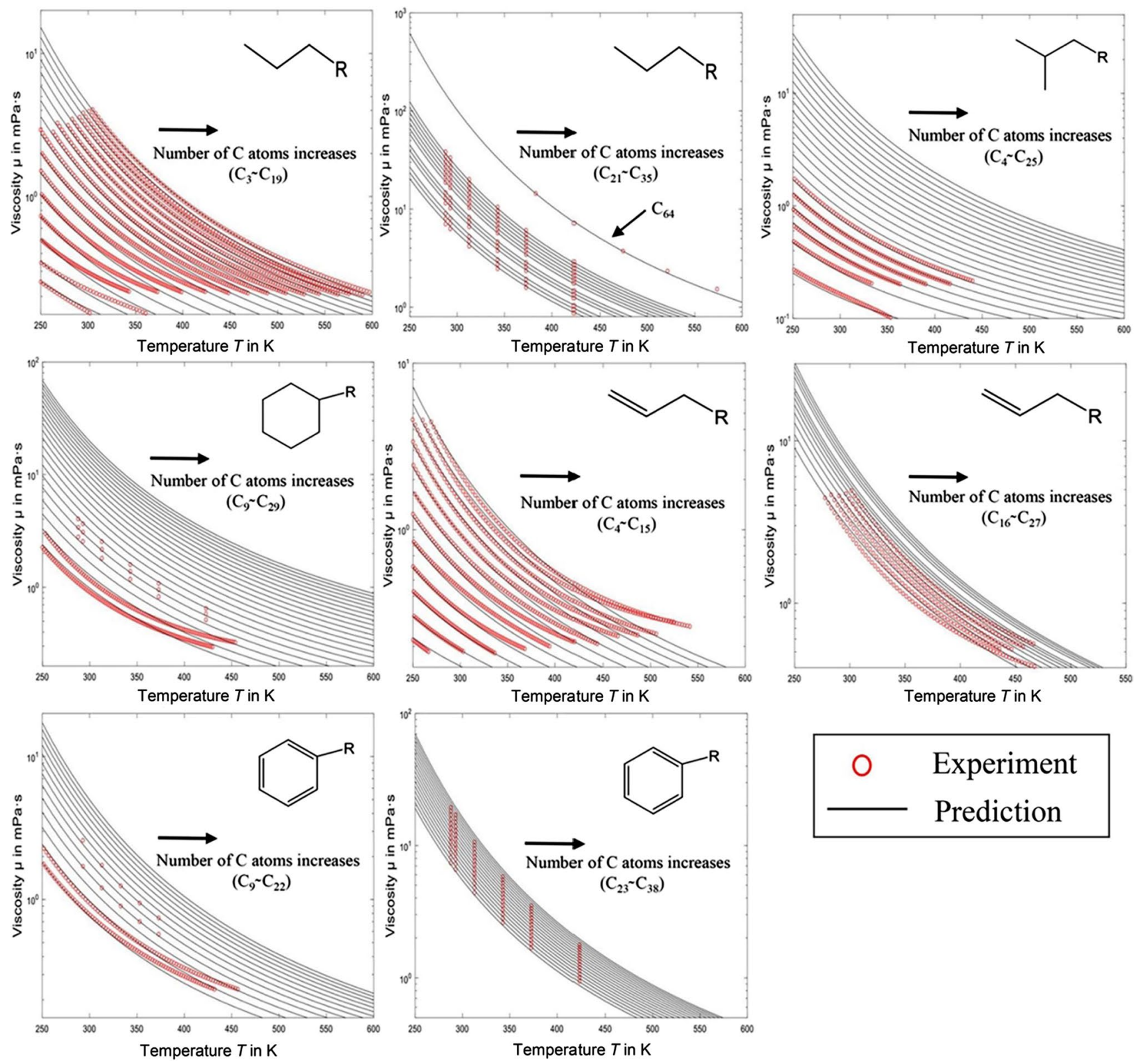

Fig. 9 Viscosity (experimental and predicted by the proposed QSPR model) of $n$-paraffin, iso-paraffin, cyclo-paraffin, olefin and aromatic homologs versus temperature (reproduced with permission from Ref. [79]) 
$\left.\mathrm{mm}^{2} / \mathrm{s}\right)$ versus trans-decalin $\left(1.75 \mathrm{~mm}^{2} / \mathrm{s}\right)$ at $40{ }^{\circ} \mathrm{C}$ [77], probably due to the increased molecular interaction caused by the twisted structure of cis configuration. The alkyl substituents also affect the viscosity of cyclo-paraffins. The increase in chain length of alkyl substituents increases the viscosity of alkyl-substituted cyclo-paraffins, e.g., methylcyclohexane $\left(0.88 \mathrm{~mm}^{2} / \mathrm{s}\right)$ versus butyl-cyclohexane $(1.22$ $\mathrm{mm}^{2} / \mathrm{s}$ ) at $40{ }^{\circ} \mathrm{C}$ [77]. Similar to density, viscosity can be affected by the position of alkyl substituents. Ortho-substituted cyclo-paraffins generally exhibit higher viscosity than meta- and para-substituted cyclo-paraffins possibly because of the more compact molecular structure of ortho-substituted cyclo-paraffins, e.g., cis-1,2-dimethylcyclohexane (1.40 $\left.\mathrm{mm}^{2} / \mathrm{s}\right)$ versus cis-1,4-dimethylcyclohexane $\left(1.12 \mathrm{~mm}^{2} / \mathrm{s}\right)$ at $20{ }^{\circ} \mathrm{C}[15]$. n-Paraffins generally have a slightly higher viscosity than iso-paraffins. Geist and Cannon [15] evaluated the viscosity of 18 chemical isomers of octane and observed that not all isomeric octanes exhibit lower kinematic viscosity than n-octane, indicating that the branching level of saturated hydrocarbons can also affect fuel viscosity.

Aromatics can increase the aviation fuel viscosity [80], and their contributions to fuel viscosity vary with their molecular size and structures. Solash et al. [68] observed that the kinematic viscosity of coal-derived fuels increases steadily in a linear manner with the average molecular size of aromatics. Dixonand Clark [81] reported that the viscosity of alkylbenzenes increases with the number of substituted methyl groups, because the hyperconjugation effect of the aromatic ring and methyl group restricts the flow of alkylbenzenes. The position of alkyl substituents can also affect the aromatic viscosity. Similar to cyclo-paraffins, ortho-substituted aromatics usually have a higher viscosity compared with meta- and para-substituted aromatics, e.g., $o$-xylene $\left(0.922 \mathrm{~mm}^{2} / \mathrm{s}\right)$ versus $p$-xylene $\left(0.784 \mathrm{~mm}^{2} / \mathrm{s}\right)$ at $20{ }^{\circ} \mathrm{C}$ [15]. Overall, fuel viscosity is determined by the total carbon number, hydrocarbon class, and molecular structure.

\section{Correlation and Estimation of Viscosity}

As a thermodynamic property, the viscosity of blended fuels can be estimated by the Grunberg-Nissan equation [82-84]:

$\ln \eta_{\text {mix }}=\sum_{i=1}^{n} x_{i} \ln \eta_{i}+\frac{1}{2} \sum_{i=1}^{n} \sum_{j=1, j \neq i}^{n} x_{i} x_{j} G_{i j}$

where $\eta_{\text {mix }}$ and $\eta_{i}$ are the dynamic viscosity of fuel mixture and $i$ th fuel component in $\mathrm{mPa} \cdot \mathrm{s}$, respectively. $x_{i}$ and $x_{j}$ are the molar fractions of the fuel components $i$ and $j$, respectively. $G_{i j}$ is the interaction parameter between $i$ th and $j$ th fuel component in $\mathrm{mPa}$ s, and $n$ is the total number of fuel components in the mixture.

Many studies attempted to estimate viscosity on the basis of molecular structure [56, 57, 73, 79]. Cai et al. [79] proposed a QSPR model to predict the hydrocarbon viscosity based on the basic groups, united group, and $M$ of fuels. To simplify the relationship of viscosity and fuel composition, Yue et al. [60] correlated viscosity with the $\mathrm{H} / \mathrm{C}$ molar ratios and $M$ of hydrocarbon fuels by using an exponential regression model. To broaden the applicability of the model, we correlated the kinematic viscosities of 23 hydrocarbon fuels at $-20{ }^{\circ} \mathrm{C}$ (Table S1, SI) with $\mathrm{H} / \mathrm{C}$ molar ratios and $M$ by the exponential regression method (Fig. 10). The exponential regression (Eq. (9)) for kinematic viscosity and $n_{\mathrm{H} / \mathrm{C}}$ $/ M^{0.54}$ indicates that the hydrocarbon fuels with low $\mathrm{H} / \mathrm{C}$ molar ratios and high $M$ preferentially have high viscosities.

$v\left(\mathrm{~mm}^{2} / \mathrm{s}\right)=1.898 \times 10^{4} \mathrm{e}^{-57.036 \times n_{\mathrm{H} / \mathrm{C}} / M^{0.54}}\left(R^{2}=0.91\right)$

where $v$ is the kinematic viscosity of hydrocarbon fuel in $\mathrm{mm}^{2} / \mathrm{s}$.

\section{Freezing Point}

\section{Relationship Between Freezing Point and Fuel Composition}

Freezing point, as a key property to describe the low-temperature fluidity of fuel, is the temperature at which the solid wax and ice crystals formed in the previous cooling vanish when heated slowly $[50,85]$. Aviation fuels operated at extremely low temperatures (or high altitudes) require a low freezing point to avoid the formation of hydrocarbon crystals that can cause clogging of the fuel supply system and other machine or operation problems $[86,87]$. The freezing point of Jet A should be lower than $-40.0{ }^{\circ} \mathrm{C}$, whereas the requirement for Jet A-1 is specified to be lower than $-47.0^{\circ} \mathrm{C}$ according to ASTM D7566-18. The freezing point of hydrocarbon fuel is a crystallization behavior, in which molecular symmetry and intermolecular forces play the key

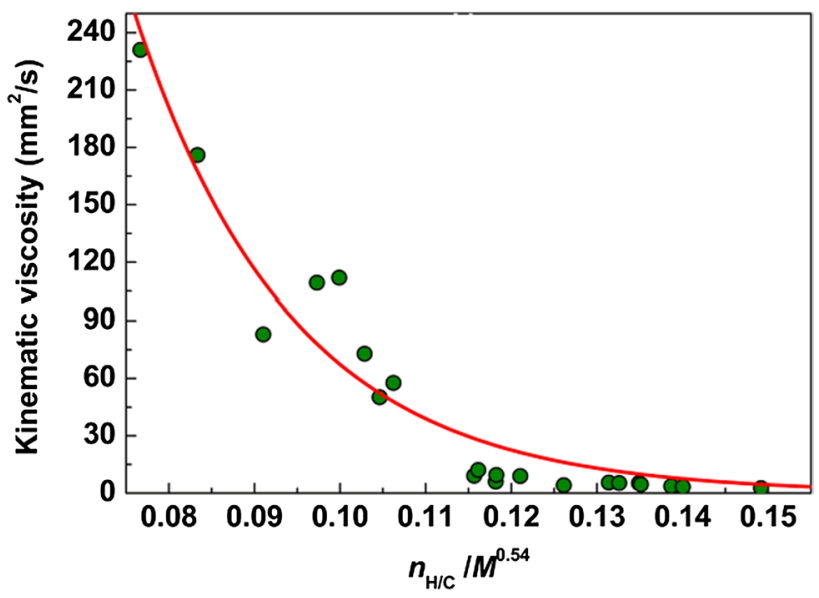

Fig. 10 Kinematic viscosity of 23 hydrocarbon fuels at $-20{ }^{\circ} \mathrm{C}$ versus $n_{\mathrm{H} / \mathrm{C}} / M^{0.54}$ 
roles $[55,88]$. By measuring the freezing point of hydrocarbon mixtures, Affens et al. [86] reported that the data derived from Van't Hoff equation of certain hydrocarbon mixtures were not in agreement with the literature data due to the strong intermolecular forces of the mixtures.

One important factor affecting the freezing point is the carbon chain length of hydrocarbon fuels; the freezing point of hydrocarbons increases with the number of total carbon atoms $[88,89]$. Thus, catalytic hydrocracking of aviation fuels is a promising method to reduce the freezing point by shortening the carbon chain length $[5,90]$.

The freezing point can be controlled by fuel chemical composition and strongly depends on the hydrocarbon class $[4,5,89]$. For a given carbon number, n-paraffins have the highest freezing point compared with other hydrocarbon classes because of their strong molecular interaction $[1,68,86,89,91]$, whereas iso-paraffins with more compact and symmetry molecular structure exhibit a higher freezing point. As shown in Fig. 11a, the freezing point of hydrocarbon fuel blends containing n-, iso-, and cycloparaffins increases with the n-paraffin content [4]. By contrast, increasing iso-paraffin concentration can reduce the freezing point [4]. Coetzer et al. [88] reported a similar observation and showed that the high mass ratio of iso- to n-paraffins contributes to the low freezing point of aviation fuels. Hence, the catalytic hydroisomerization of n-paraffins to iso-paraffins also decreases the freezing point of aviation fuels [90, 91]. Although the effect of cyclo-paraffin content on the freezing point has no visible regularity (Fig. 11b) [4], the alkyl-substituted cyclo-paraffins generally exhibit a low freezing point $[92,93]$.

The effect of aromatic components on the freezing point has been also investigated. Hong et al. [94] noted that the addition of propylbenzene can reduce the freezing point of bio-jet fuel mixture (Fig. 11c). Similarly, Al-Nuaimi et al. [19] observed that GTL SPK blended with the conventional jet fuels has a low freezing point owing to the introduction of aromatics. The position of alkyl substituents can also affect the freezing point of aromatics. For instance, $p$-xylene $\left(13.2^{\circ} \mathrm{C}\right)$ exhibits a notably higher freezing point than $o$-xylene $\left(-25.2^{\circ} \mathrm{C}\right)$ and $m$-xylene $\left(-47.9^{\circ} \mathrm{C}\right)$ due to its better molecular symmetry.

In addition to the molecular structure, the average carbon number influences the freezing point. As shown in Table 1 , JP-4 has the lowest freezing point temperature $\left(-62.2^{\circ} \mathrm{C}\right)$ among the summarized fuels due to its relatively low average number of carbon atoms. S-8 and Chinese RP-3 jet fuels have a high average carbon number, but their freezing points are as low as $-59.0^{\circ} \mathrm{C}$ and $-58.0^{\circ} \mathrm{C}$, respectively, owing to the high concentration of iso-paraffins, i.e. $82.0 \mathrm{wt} \%$ for S-8 [22] and $42.7 \mathrm{wt} \%$ for RP-3 [23].

Overall, hydrocarbon fuels with high molecular symmetry and intermolecular force generally have a high freezing point. Specifically, the freezing point of hydrocarbon increases with the number of total carbon atoms. For the same average carbon number, iso-paraffins and aromatics possess relatively low freezing points, whereas n-paraffin fuels show a high freezing point. Hence, the catalytic hydrocracking and hydroisomerization of aviation fuels are major methods used to reduce the freezing point.

\section{Correlation and Estimation of Freezing Point}

Al Mulla and Albahri [95] proposed an empirical method to calculate the freezing point based on the blending freezing point index $\left(I_{\text {fr,blend }}\right)$, which is determined by the freezing point index of each fuel component, that can be calculated by the following equation:

$$
I_{i}=3.23 \times 10^{-6} \times 1.067^{T_{\mathrm{fr}, i}}
$$
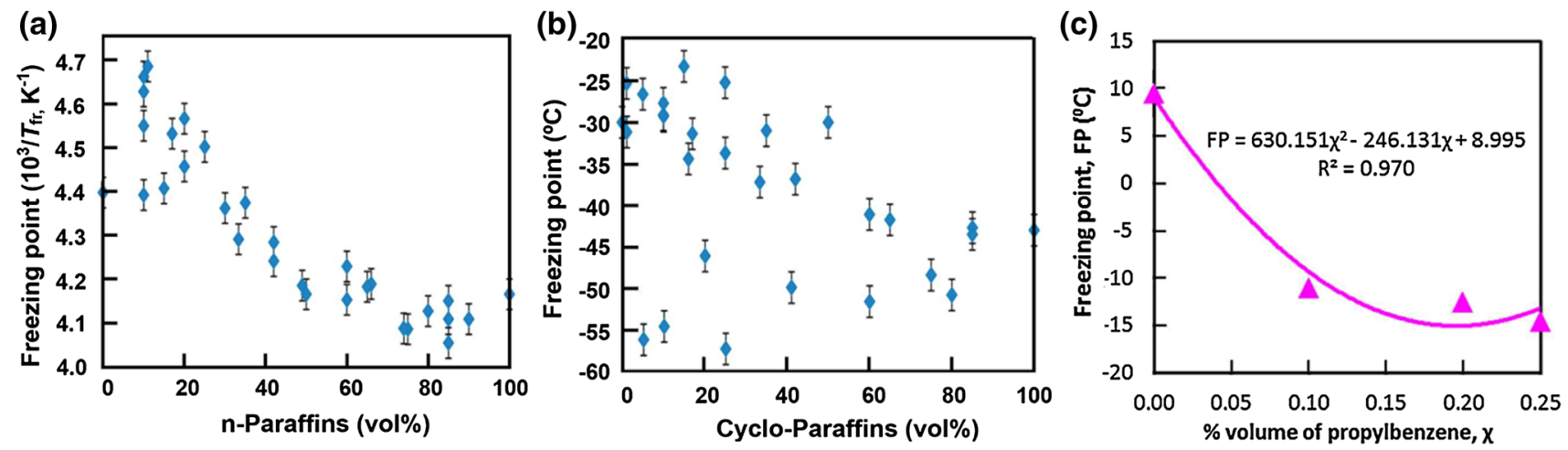

Fig. 11 Freezing point of hydrocarbons versus a n-paraffin volume content (in which the freezing point is represented by the reciprocal of absolute temperature) and $\mathbf{b}$ cyclo-paraffin volume content of fuel blends consisting of n-, iso-, and cyclo-paraffins (reproduced with permission from Ref. [4]); c propylbenzene volume content of bio-jet fuels (reproduced with permission from Ref. [94]) 
where $I_{i}$ and $T_{\mathrm{fr}, i}$ are the freezing point index and the freezing point of $i$ th fuel component in $\mathrm{K}$, respectively. The blending freezing point index $\left(I_{\text {fr,blend }}\right)$ can be obtained by Eq. (11).

$I_{\mathrm{fr}, \text { blend }}=\sum\left(v_{i} \times I_{i}\right)$

where $v_{i}$ is the volume fraction of the $i$ th fuel component, and $I_{\mathrm{fr}, \mathrm{blend}}$ is the freezing point index of the fuel blend. Therefore, the freezing point of fuel blends can be calculated by Eq. (12).

$T_{\mathrm{fr}}=193.798+15.379 \times \ln \left(I_{\text {fr,blend }}\right)$

where $T_{\mathrm{fr}}$ is the freezing point of the fuel blend in K.

Cookson et al. [50, 52, 53] used the MLR method to correlate the freezing point and the fuel composition detected by HPLC, GC, and ${ }^{13} \mathrm{C}$ NMR (Entries $1-4$, Table 5); the boiling range was introduced to develop several expressions (Entry 5, Table 5) [53]. Liu et al. [54] used GC-MS to determine the content of eight hydrocarbon classes and further correlated the freezing point by the ANN method (Entries 6-7, Table 5). Moreover, Shi et al. [55] classified the aviation fuel composition under 10 hydrocarbon classes and using the carbon number $\left(\mathrm{C}_{7}-\mathrm{C}_{19}\right)$ obtained by $\mathrm{GC} \times \mathrm{GC}-\mathrm{MS} / \mathrm{FID}$ and used different statistical algorithms to correlate the freezing point and chemical composition. Hong et al. [94] correlated the freezing point of fuel blends with the volume content of propylbenzene (Entry 8, Table 5). Al-Nuaimi et al. [19] proposed several multiple nonlinear correlations between the freezing point and the composition of fuel blends composed of n-, iso- and cyclo-paraffins to predict the freezing points of blending fuels (Entry 9, Table 5). Analogous to the density and NHOC, PLS regression method based on FT-IR spectra can also predict the fuel freezing point [58].
To simplify the relationship between the freezing point and molecular structure of aviation fuels, we attempted to correlate the freezing point with $\mathrm{H} / \mathrm{C}$ molar ratios and $M$; however, we failed to obtain a suitable model probably given the difficulty of reflecting molecular symmetry and intermolecular forces [55, 88].

\section{Flash Point}

Flash point is the minimum temperature at which a volatile fuel produces sufficient amount of vapor needed for the ignition with air upon encountering an external energy source, i.e., a spark or a flame [54, 55, 96-98]. In other words, flash point is the temperature at which flammable and ignitable vapor-air mixtures above the liquid fuel corresponds to a low flammable limit $[54,55,99]$. The flash point is an important physical property for the fire safety of processing, transportation, storage, and usage of fuel [100-102].

\section{Relationship Between Flash Point and Fuel Composition}

The flash point of hydrocarbon fuels can be measured using closed-cup or open-up methods [97, 99, 103]. For aviation fuels, the flash point obtained by closed-cup methods is greater than $38.0{ }^{\circ} \mathrm{C}$ according to ASTM D7566-18 and D1655-18. In general, the flash point, such as the $10 \%$ boiling point $\left(T_{10}\right.$, the temperature at which the distillate volume reaches $10 \%$ of the fuel sample) which represents the initial behavior of distillation [76], is a linear function of the
Table 5 Correlations between freezing point and fuel composition

\begin{tabular}{llr}
\hline Entry & Developed correlative models & References \\
\hline $1^{\mathrm{a}}$ & $T_{\mathrm{fr}}\left({ }^{\circ} \mathrm{C}\right)=-0.8 \omega_{\mathrm{n}}-63.8 \omega_{\mathrm{bc}}-55.9 \omega_{\mathrm{ar}}$ & {$[50]$} \\
2 & $T_{\mathrm{fr}}\left({ }^{\circ} \mathrm{C}\right)=-12.7 \omega_{\mathrm{n}}-61.0 \omega_{\mathrm{bc}}-50.4 \omega_{\mathrm{ar}}$ & {$[50]$} \\
$3^{\mathrm{b}}$ & $T_{\mathrm{fr}}\left({ }^{\circ} \mathrm{C}\right)=49.8 C_{\mathrm{n}}-18.1 C_{\mathrm{ar}}-61.6$ & {$[52]$} \\
4 & $T_{\mathrm{fr}}\left({ }^{\circ} \mathrm{C}\right)=81.3 C_{\mathrm{n}}-62.8 C_{\mathrm{ar}}-86.4$ & {$[53]$} \\
$5^{\mathrm{c}}$ & $T_{\mathrm{fr}}\left({ }^{\circ} \mathrm{C}\right)=81.1 C_{\mathrm{n}}+53.6 C_{\mathrm{ar}}+0.255 T_{10}+0.338 T_{90}-206.2$ & {$[53]$} \\
$6^{\mathrm{d}}$ & $T_{\mathrm{fr}}\left({ }^{\circ} \mathrm{C}\right)=53.88 C_{\mathrm{n}}-32.53 C_{\mathrm{iso}}-10.91 C_{\mathrm{cyclo}}-3.79 C_{\mathrm{ar}}-50.86$ & {$[94]$} \\
7 & $T_{\mathrm{fr}}\left({ }^{\circ} \mathrm{C}\right)=59.2 C_{\mathrm{n}}-21.14 C_{\mathrm{iso}}-13.04 C_{\mathrm{cyclo}}+41.99 C_{\mathrm{ar}}+0.557 T_{10}-0.212 T_{90}+44.32$ & {$[54]$} \\
$8^{\mathrm{e}}$ & $T_{\mathrm{fr}}\left({ }^{\circ} \mathrm{C}\right)=630.151 \chi^{2}-246.131 \chi+8.995$ & {$[19]$} \\
$9^{\mathrm{f}}$ & $T_{\mathrm{fr}}\left({ }^{\circ} \mathrm{C}\right)=243.15 x_{\mathrm{n}-\mathrm{p}}+196.15 x_{\mathrm{iso}-\mathrm{p}}^{0.902}+230.15 x_{\text {cyclo-p }}$ & \\
\hline
\end{tabular}

${ }^{\mathrm{a}} T_{\mathrm{fr}}$ is the freezing point of aviation fuel in ${ }^{\circ} \mathrm{C}$, and $\omega_{\mathrm{n}}, \omega_{\mathrm{bc}}$, and $\omega_{\mathrm{ar}}$ are the mass fractions of n-paraffins, cyclo-paraffins plus iso-paraffins, and aromatics, respectively. ${ }^{\mathrm{b}} C_{\mathrm{n}}$ and $C_{\mathrm{ar}}$ are the fractions of $\mathrm{n}$-alkyls and aromatic carbons, respectively. ${ }^{\mathrm{c}} T_{10}$ and $T_{90}$ represent the temperatures at which up to $10 \mathrm{wt} \%$ and $90 \mathrm{wt} \%$ hydrocarbon fuels are distilled, respectively. ${ }^{\mathrm{d}} C_{\text {iso }}$ and $C_{\text {cyclo }}$ are the fractions of iso-alkyls and naphthenic carbon, respectively. ${ }^{\mathrm{e}} \chi$ represents the volume fraction of propylbenzene in the fuel blend. ${ }^{\mathrm{f}} x_{\mathrm{n}-\mathrm{p}}, x_{\text {iso-p }}$, and $x_{\text {cyclo-p }}$ are the mole fractions of $\mathrm{n}-$, iso-, and cyclo-paraffins, respectively 

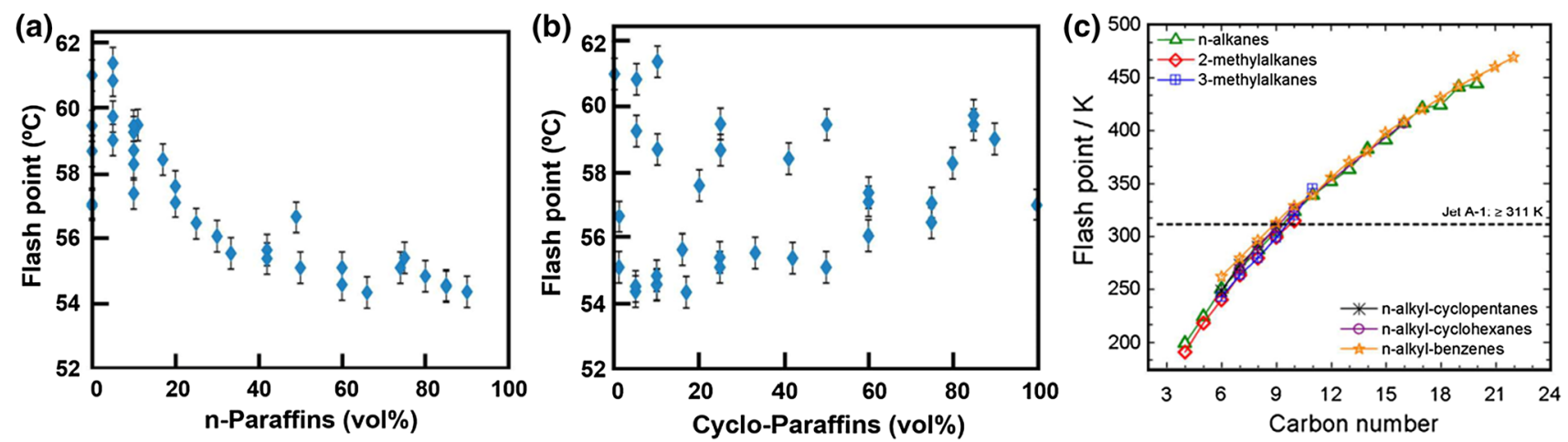

Fig. 12 Flash point versus a n-paraffin and $\mathbf{b}$ cyclo-paraffin volume content of fuel blends consisting of n-, iso-, and cyclo-paraffins (reproduced with permission from Ref. [4]); $\mathbf{c}$ the total carbon number of several hydrocarbon classes (reproduced with permission from Ref. [1])

boiling point of hydrocarbon fuels [103]. From Table 1, the flash point is positively related to $T_{10}$, and JP-4 has a low flash point due to its low $T_{10}$.

The chemical composition of hydrocarbon fuels can affect the flash point, especially the low-flash-point fuel components [65]. Elmalik et al. [4] reported that the increase in $n$-paraffin concentration results in a linear decrease in the flash point of hydrocarbon blends composed of n-, iso-, and cyclo-paraffins due to the low flash point of n-paraffins, whereas the effect of cyclo-paraffin content on the flash point is unclear (Fig. 12a, b). Scheuermann et al. [58] reported that the introduction of aliphatic compounds with a low boiling point reduces the fuel flash point, whereas hydrocarbon fuels containing high-boilingpoint aromatics exhibit high flash points. Typically, the flash point of iso-paraffins is lower than that of n-paraffins, and iso-paraffins with more molecular branches have a lower flash point at a given carbon number, e.g., 2,3-dimethylpentane $\left(-6.2^{\circ} \mathrm{C}\right)$ versus 2,2,4-trimethylpentane (TMP) $\left(-12.2^{\circ} \mathrm{C}\right)[104]$.

Cyclo-paraffins usually possess a slightly higher flash point than n-paraffins at the same carbon number, and cyclo-paraffins with cis configuration have a higher flash point than their trans configuration, e.g., cis-decalin $\left(59.5{ }^{\circ} \mathrm{C}\right)$ versus trans-decalin $\left(53.7{ }^{\circ} \mathrm{C}\right)$ [13] possibly due to the increased molecular interaction caused by the twisted structure of cis configuration. The position of alkyl substituent also influences the flash point of cyclo-paraffins. Ortho-substituted cyclo-paraffins generally have a higher flash point than para- and meta-substituted cycloparaffins, e.g., cis-1,2-dimethylcyclohexane $\left(11.9{ }^{\circ} \mathrm{C}\right)$ versus cis-1,4-dimethylcyclohexane $\left(5.9^{\circ} \mathrm{C}\right)$ [104]. Similar to that of cyclo-paraffins, the flash point of aromatics can be influenced by the position of alkyl substituents, whereas the flash point of ortho-substituted aromatics is usually higher than that of para- and meta-substituted cyclo-paraffins, e.g., $o$-xylene $\left(31.9^{\circ} \mathrm{C}\right)$ versus $m$-xylene $\left(24.9^{\circ} \mathrm{C}\right)$ [104]. As illustrated in Fig. 12c, the flash point of all hydrocarbons (including paraffins, cyclo-paraffins, and aromatics) increases with the number of total carbon atoms [1].

\section{Correlation and Estimation of Flash Point}

Obtaining the experimental flash point of fuels is time-consuming and costly, especially for newly synthesized fuels; meanwhile, the methods for estimating and evaluating the flash point of aviation fuels are of considerable interest [97]. Wickey and Chittenden [105] proposed an experimental method to predict the flash point of fuel blends through the blending flash point index $\left(I_{\text {ffl,blend }}\right)$ obtained by using the flash point index of each fuel component; the calculation is as Eq. (13).

$\lg \left(I_{i}\right)=-6.1188+\frac{2414}{T_{\mathrm{fl}, i}+503.71}$

where $I_{i}$ and $T_{\mathrm{fl}, i}$ are the flash point index and flash point in $\mathrm{K}$ of the $i$ th fuel component, respectively. The blending flash point index can be obtained by Eq. (14).

$I_{\mathrm{fl}, \text { blend }}=\sum\left(v_{i} \times I_{i}\right)$

where $v_{i}$ is the volume fraction of $i$ th fuel component, and $I_{\text {ff,blend }}$ is the freezing point index of fuel blend. Therefore, the prediction of flash point can be described as Eq. (15).

$T_{\mathrm{fl}}=\frac{2414}{6.118+\lg \left(I_{\text {fl, blend }}\right)}+42.59$

where $T_{\mathrm{ff}}$ is the flash point of fuel blend in $\mathrm{K}$. 
Table 6 Correlations between flash point and fuel composition

\begin{tabular}{llll}
\hline Entry & Developed correlative models & References \\
\hline $1^{\mathrm{a}}$ & $T_{\mathrm{fl}}\left({ }^{\circ} \mathrm{C}\right)=-46.14 C_{\mathrm{n}}-55.21 C_{\text {iso }}-41.77 C_{\text {cyclo }}-98.96 C_{\text {ar }}+126.25$ & \\
$2^{\mathrm{b}}$ & $T_{\mathrm{fl}}\left({ }^{\circ} \mathrm{C}\right)=12.82 C_{\mathrm{n}}+8.94 C_{\text {iso }}+11.09 C_{\text {cyclo }}+23.01 C_{\text {ar }}+0.8836 T_{10}-0.0479 T_{90}-108.86$ & {$[54]$} \\
$3^{\mathrm{c}}$ & $T_{\mathrm{fl}}\left({ }^{\circ} \mathrm{C}\right)=\left(157.6 x_{\mathrm{n}-\mathrm{p}}+168.6 x_{\text {iso-p }}+140.3 x_{\text {cyclo-p }}\right)+\left(10 x_{\mathrm{n}-\mathrm{p}}+12 x_{\text {iso-p }}+10 x_{\text {cyclo-p }}\right)$ & {$[54]$} \\
$4^{\mathrm{d}}$ & $T_{\mathrm{fl}}\left({ }^{\circ} \mathrm{C}\right)=114.94-6.213 \times 10^{5} n_{\mathrm{H} / \mathrm{C}} / M^{2}$ & {$[19]$} \\
\hline
\end{tabular}

${ }^{\mathrm{a}} T_{\mathrm{fl}}$ is the flash point of aviation fuels in ${ }^{\circ} \mathrm{C}$, and $C_{\mathrm{n}}, C_{\mathrm{iso}}, C_{\text {cyclo }}$, and $C_{\mathrm{ar}}$ are the fractions of n-alkyls, iso-alkyls, naphthenic carbon, and aromatic carbon, respectively. ${ }^{\mathrm{b}} T_{10}$ and $T_{90}$ represent the temperatures at which up to $10 \mathrm{wt} \%$ and $90 \mathrm{wt} \%$ of hydrocarbon fuels are distilled, respectively. ${ }^{\mathrm{c}} x_{\mathrm{n}-\mathrm{p}}, x_{\text {iso-p }}$, and $x_{\text {cyclo-p }}$ are the mole fractions of n-, iso-, and cyclo-paraffins, respectively. ${ }^{\mathrm{d}} n_{\mathrm{H} / \mathrm{C}}$ and $M$ are the hydrogen-to-carbon molar ratio and molecular weight, respectively

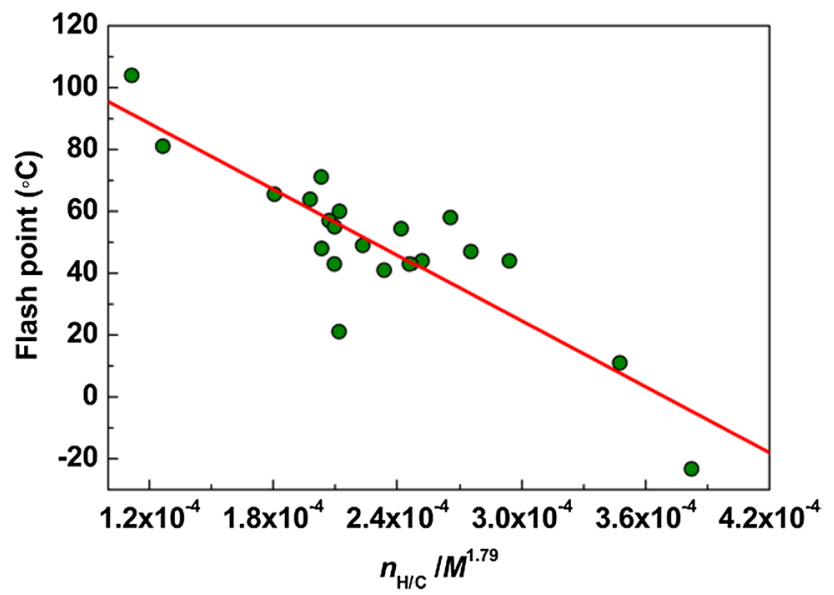

Fig. 13 Flash points of 23 typical hydrocarbon fuels versus $n_{\mathrm{H} / \mathrm{C}}$ $/ M^{1.79}$

Vidal [106], Liu [107], and Phoon et al. [97] reviewed the studies on the prediction methods of flash point of flammability liquid mixtures. Such prediction methods can be categorized into boiling-point- or composition-range-based, molecular-structure-based, and vapor-pressure-based methods [97].

Given that flash point is related to the chemical composition, especially the carbon number of hydrocarbon fuels, several methods are used to predict and correlate the flash point based on fuel composition (Table 6). Liu et al. [54] used the ANN method to estimate the flash point based on the content of eight hydrocarbon classes of aviation fuels obtained from GC-MS, with a high $R^{2}$ of 0.90 (Entries 1-2, Table 6). Al-Nuaimi et al. [19] predicted the flash point of hydrocarbon mixtures based on the mole fractions and carbon number of n-, iso- and cyclo-paraffins, with a $R^{2}$ of 0.75 (Entry 3, Table 6). Shi et al. [55] further developed the quantitative composition-flash point relationship of jet fuels with statistical algorithms by determining the detailed composition based on $\mathrm{GC} \times \mathrm{GC}-\mathrm{MS} / \mathrm{FID}$. Yue et al. [60] correlated the flash point of 14 kinds of hydrocarbon fuels with the $\mathrm{H} / \mathrm{C}$ molar ratio and $M$ by using the linear regression method, achieving a $R^{2}$ of 0.85 (Entry 4 , Table 6).
Furthermore, we correlated the flash point of 23 typical hydrocarbon fuels (Table S1, SI) with the H/C molar ratio and $M$ using the least-square method (Fig. 13). The linear regression equation between the flash point and molecular structure $(\mathrm{H} / \mathrm{C}$ molar ratio and $M)$ can be described as Eq. (16), and the flash point decreases with the increase in $n_{\mathrm{H} / \mathrm{C}} / M^{1.79}$. However, the precise prediction of the flash point remains challenging, thus indicating the need for in-depth investigations.

$T_{\mathrm{fl}}=131.008-3.548 \times 10^{5} \times n_{\mathrm{H} / \mathrm{C}} / M^{1.79}\left(R^{2}=0.73\right)$

\section{Thermal-Oxidative Stability}

In addition to propellants, aviation fuels are used as primary coolants to absorb the waste heat from the aero-engine system and other aircraft components. However, the rising temperature of fuels causes the formation of insoluble deposits, which may reduce the heat transfer efficiency and clog valves and filters in piping and engine systems [108]. Thermal-oxidative stability refers to the resistance of aviation fuels to self-oxidation, decomposition, and undesirable carbon deposit formation, which can be attributed to several liquid-phase oxidation reactions, at the operating temperature for a short time. Thermal-oxidative stability can be described by thermal and oxidative stabilities, which can be assessed by the jet fuel thermal oxidation stability test (JFTOT) described in ASTM D3241 and the rapid smallscale oxidation test defined in ASTM D7545, respectively $[5,109]$.

\section{Thermal Stability}

The thermal stability of aviation fuels refers to their sensitivity to self-oxidation degradation and the capability to resist fuel deterioration for a certain period at elevated temperatures [110]. JFTOT is the standard test method to quantitatively measure the thermal deposit formation of aviation 
fuels from two aspects: the surface deposit on the test tube evaluated by visual tube rating (VTR) methods and the filter pressure drop after the test $[5,110]$. The VTR color code should be less than 3 (range: $0-4$; the larger the number, the heavier the deposit), and the filter pressure drop should be less than $25 \mathrm{mmHg}$ (ASTM D7566-18 and D1655-18).

The thermal stability of jet fuels can be affected by numerous factors, including temperature, pressure, fuel composition, heteroatom content, and the catalytic activity of metal surfaces. Apart from temperature and pressure, thermal stability is determined by fuel composition and heteroatom content. In general, hydrocarbon fuels containing high concentration of aromatics and heteroatom-containing species exhibit intense deposit-forming tendency [111]. For instance, JP-8 exhibits poorer thermal stability than paraffinic fuels obtained from F-T synthesis or hydrogenation process due to its heteroatom-containing compounds [91], whereas synthetic fuels with low concentrations of aromatics and heteroatom components have higher thermal stability than crude fuels [111].

The presence of trace of heteroatom-containing compounds (e.g., thiophene $\left(\mathrm{C}_{4} \mathrm{H}_{4} \mathrm{~S}\right)$, phenols $\left(\mathrm{C}_{6} \mathrm{H}_{6} \mathrm{O}\right)$, pyrroles $\left(\mathrm{C}_{4} \mathrm{H}_{5} \mathrm{~N}\right)$, anilines $\left(\mathrm{C}_{6} \mathrm{H}_{7} \mathrm{~N}\right)$, indoles $\left(\mathrm{C}_{8} \mathrm{H}_{7} \mathrm{~N}\right)$, quinolines $\left(\mathrm{C}_{9} \mathrm{H}_{7} \mathrm{~N}\right)$, and carbazoles $\left.\left(\mathrm{C}_{12} \mathrm{H}_{9} \mathrm{~N}\right)\right)$ has a negative influence on thermal stability [112] given their capability to form macromolecules that can enhance deposit formation. Beaver et al. [113] proposed that electron-rich heteroatom aromatic species, such as phenols, arylamines, and thiophenols, can be involved in the formation of fuel deposits. The existence of benzothiophenes $\left(\mathrm{C}_{8} \mathrm{H}_{6} \mathrm{~S}\right)$ and other sulfur-containing cyclic compounds can reduce the breakpoint temperature (the highest temperature at which a fuel can meet the specification of VTR and filter pressure drop) of petroleum-based fuels, as reported by Westhuizen et al. [111]. Similarly, the breakpoint temperature of F-T fuel is notably higher than that of Jet A $\left(370{ }^{\circ} \mathrm{C}\right.$ for F-T fuel versus $270{ }^{\circ} \mathrm{C}$ for Jet A) due to the lower concentration of heteroatom-containing species and aromatics in F-T fuel [114]. On this basis, Jia et al. [16] applied the catalytic hydrogenation method to treat Chinese RP-3 jet fuel to remove the heteroatom components (e.g., sulfurs and phenols) and aromatic contents, thus promoting the fuel's thermal stability.

DeWitt et al. [110] proposed that the oxidation and molecular growth of aromatics are the major routes for the deposit formation of SPK/aromatic fuel blends; these authors also stated that less steps are required for the growth of aromatics with high molecular size into insoluble deposit precursors. Ben Amara et al. [109] measured the thermal stability of HEFA aviation fuel with the addition of different aromatics by JFTOT test at $325^{\circ} \mathrm{C}$. As illustrated in Fig. 14a, the VTR color code and pressure drop of HEFA can satisfy the requirement of ASTM D7566-18, whereas the addition of xylene (25\%), 1-methylnaphtalene ( $\geq 5 \%)$, and tetralin $(\geq 15 \%)$ leads to the tube deposit rating above 3 .
Fig. 14 Assessment of thermal stability for HEFA aviation fuel and its blend fuels with different contents of aromatics from two metrics: a test tube deposit rating and $\mathbf{b}$ filter pressure drop after JFTOT test (reproduced with permission from Ref. [109])
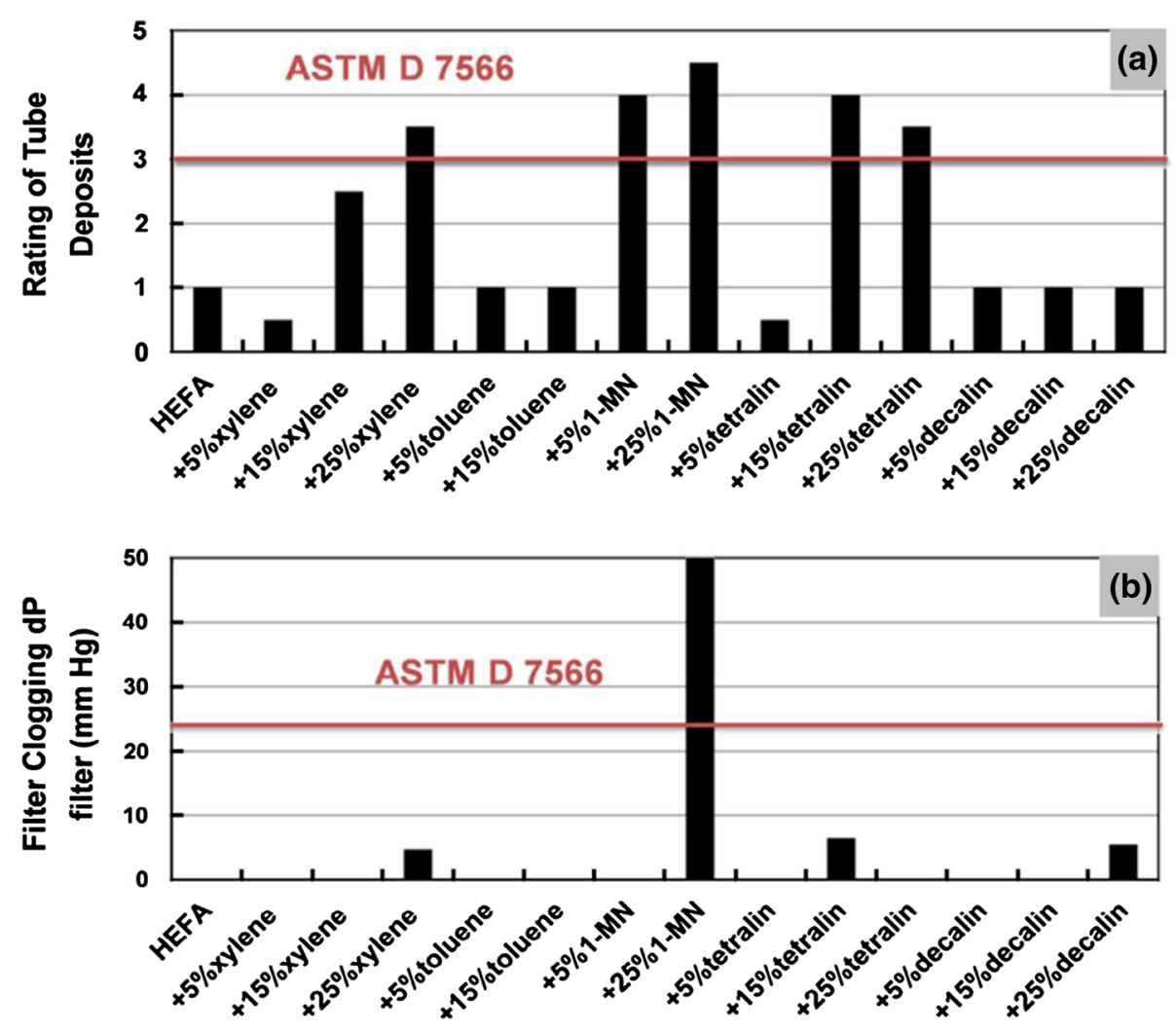
Unexpectedly, the addition of 5\% of xylene and tetralin can enhance the thermal stability of HEFA with the VTR color code less than 1 . Only the pressure drop of 1-methylnaphtalene/HEFA (25/75) is higher than $25 \mathrm{mmHg}$ (Fig. 14b), indicating that diaromatics can substantially reduce the thermal stability of aviation fuels.

\section{Oxidative Stability}

The oxidative stability of aviation fuels, different from thermal stability, emphasizes the propensity to react with the surrounding/dissolved oxygen at a moderate temperature to produce peroxides $[115,116]$; this condition initiates thermal deposition. Although ASTM D7566-18 and D1655-18 mention no explicit stipulation for oxidative stability, the induction period (IP), which corresponds to the period needed to reach $10 \%$ oxygen pressure drop, can serve as an indicator to evaluate the oxidative stability of aviation fuels in accordance with ASTM D7545.

Fuel composition determines the oxidation stability $[116,117]$. Paraffins have a poor oxidation stability, and thus, bio-jet fuels have relatively poorer oxidative stability than conventional jet fuels owing to their higher paraffin content [5]. For example, the IP (measured under 7 bar of oxygen pressure at $140{ }^{\circ} \mathrm{C}$ according to ASTM D7545) of HEFA $(1 \mathrm{~h})$ is considerably lower than that of Jet A (2.3 h) [109]. Chatelain et al. [118] reported that the IP of n-paraffins drastically decreases with the increase in carbon chain length and levels off at carbon numbers above 12 (Fig. 15a). The increase in tertiary carbon number can reduce the oxidative stability because the carbon-hydrogen bond dissociation energy on tertiary carbons is small, and the radicals formed are stable. Chatelain et al. also evaluated the oxidative stability of $\mathrm{C}_{8}$ isomers (Fig. 15b) [119]; except that of TMP (2,2,4-trimethylpentane), the IP was inversely related to the increased branching level, which can be explained by the dissociation energy of carbon-hydrogen bond, where the carbon-hydrogen bond dissociation energy follows the order primary carbon $>$ secondary carbon $>$ tertiary carbon. For TMP, a quaternary carbon on which no hydrogen atoms can be abstracted exists.

Larsen et al. [120] reported that the oxygen consumption rate of tricyclic cyclo-paraffins at $110{ }^{\circ} \mathrm{C}$ is higher than that of n-paraffins and bicyclic cyclo-paraffins, indicating that cyclo-paraffins with more rings have poorer oxidative
Fig. 15 IP related to a the carbon chain length of n-paraffins (reproduced with permission from Ref. [118]) and $\mathbf{b}$ the branching level of octane isomers, including n-octane $\left(\mathrm{C}_{8}\right)$, 2-methylheptane, 2,5-dimethylhexane, and TMP (reproduced with permission from Ref. [119])

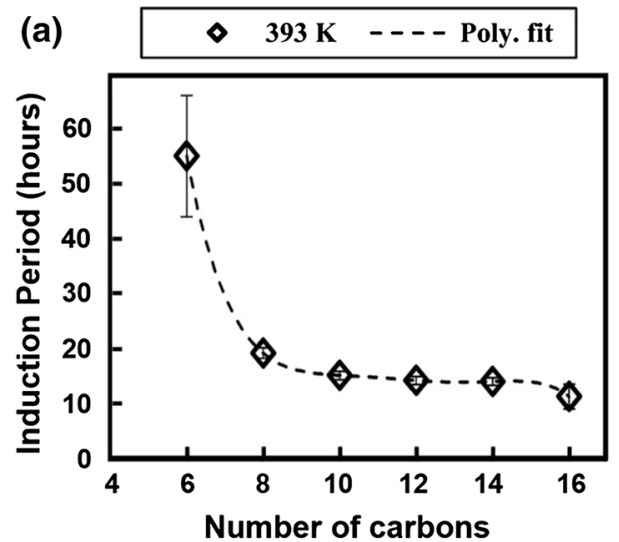

(b)
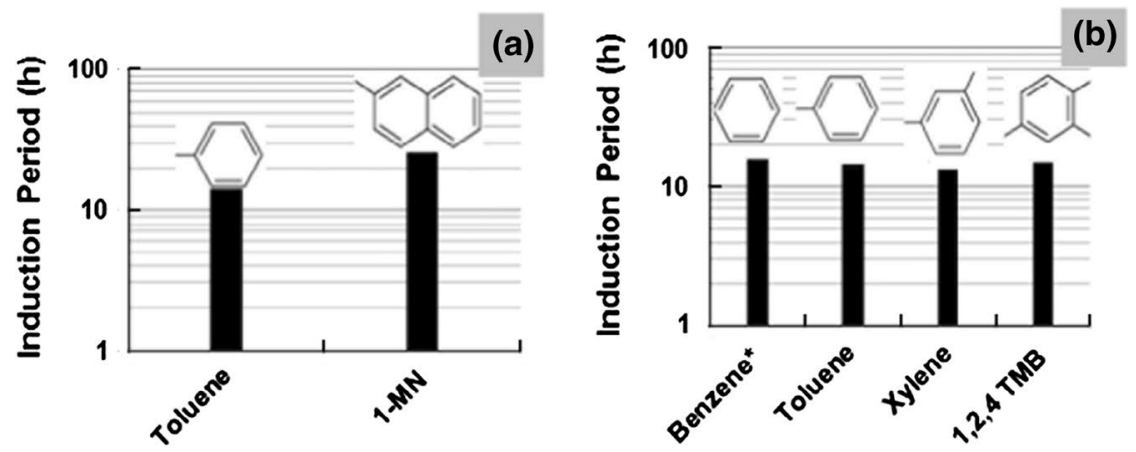

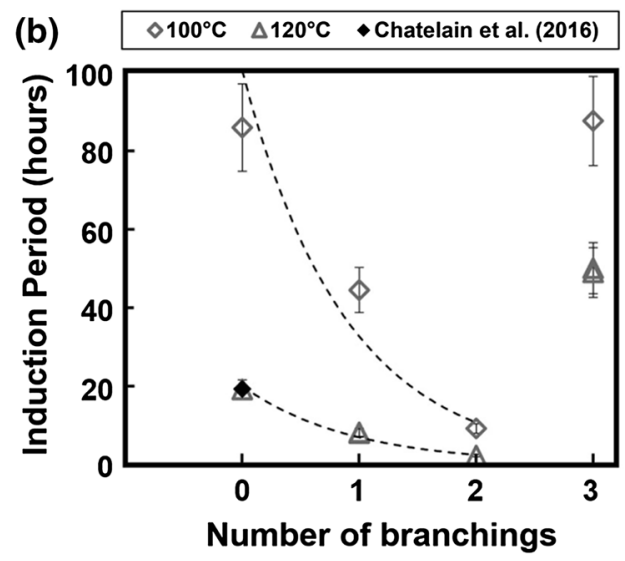

Fig. 16 IP measured at $140{ }^{\circ} \mathrm{C}$ versus a the number of benzene cycles, $\mathbf{b}$ the number of alkyl substituents on the benzene ring, and $\mathbf{c}$ the side chain length of aromatics and cyclo-paraffins (reproduced with permission from Ref. [109]) 
stability because of their increased number of tertiary carbon atoms. They also observed that alkyl-substituted cycloparaffins have a lower oxidative stability than unsubstituted cyclo-paraffins due to the increased number of tertiary carbon atoms (caused by the alkyl substituents).

Aromatics generally exhibit a higher oxidative stability than cyclo-paraffins and paraffins. For example, certain monoaromatics (1,3,5-trimethylbenzene) benefit the oxidative stability of synthetic fuels [121]; the addition of diaromatics can significantly improve the oxidative stability of HEFA [109]. From Fig. 16a, diaromatics have better oxidative stability than monoaromatics, indicating that the increase in aromatic molecular size can improve the oxidative stability, whereas the number and position of alkyl substitutes on benzene have minimal effect (Fig. 16b) [109]. As shown in Fig. 16c, aromatics have a higher oxidative stability than saturated cyclo-paraffins. Jia et al. [16] reported that the increase in hydrogenation degree of Chinese RP-3 jet fuel can cause the decrease in oxidation onset temperature and IP, both of which are positively correlated to the aromatic contents. Figure 16c also shows that the increase in side carbon length of aromatics or cyclo-paraffins contributes to a low IP [109], possibly due to the lower carbon-hydrogen bond dissociation energy of tertiary carbon in comparison with that of secondary carbon. These observations further confirm that aromatics have excellent oxidative stability compared with cyclo-paraffins and paraffins.

The chemical composition of aviation fuels can influence oxidative stability. For paraffins, the carbon chain length and branching level can influence oxidative stability. Cyclo-paraffins with more rings and alkyl substituents have poor oxidative stability. Aromatics possess better oxidative stability than cyclo-paraffins, and aromatics with a high molecular size exhibit a high oxidative stability. The number and position of alkyl substituents barely influence the oxidative stability of aromatics, whereas the increase in alkyl-substituent length reduces the aromatic oxidative stability. An inverse relationship exists between the oxidative and thermal stabilities of several aviation fuels, i.e., fuels that can be oxidized easily usually exhibit a desirable thermal stability. The relationship between oxidative and thermal stabilities should be further examined in detail.

\section{Summary}

The fundamental properties of aviation fuels are intrinsically affected by chemical composition. In this review, a series of physicochemical properties of aviation hydrocarbon fuels, including density, NHOC, low-temperature fluidity (viscosity and freezing point), flash point, and thermal-oxidative stability, were comprehensively summarized and evaluated from the perspective of detailed composition and molecular structure.

Fuel density is closely related to molecular structure, the total carbon number, and H/C molar ratio. The NHOC should be evaluated from two prospects: gravimetric and volumetric NHOC. For most hydrocarbon fuels, a high $\mathrm{H} / \mathrm{C}$ molar ratio contributes to a high gravimetric NHOC. Strained fuels with a strained ring molecular structure and low $\mathrm{H} / \mathrm{C}$ molar ratio exhibit high gravimetric NHOC. A positive correlation exists between volumetric NHOC and density. Low-temperature fluidity can be described by viscosity and freezing point. The total carbon number, hydrocarbon class, and molecular structure have significant influences on viscosity and freezing point. The flash point of aviation fuels can be influenced by low-boiling-point fuel components and the total carbon number. Thermal-oxidative stability can be categorized into thermal and oxidative stabilities. Thermal stability can be negatively affected by the contents of aromatic and heteroatom-containing species, whereas aromatics with a high molecular size can promote oxidative stability. The carbon chain length and branching level can influence the oxidative stability of paraffins. Cyclo-paraffins with multiple rings and alkyl substituents have poor oxidative stability.

Several predictions and correlations for the aviation fuel properties from the chemical composition reported in the literature were outlined. The results obtained from the least-square method indicate that the fuel density, gravimetric $\mathrm{NHOC}$, volumetric $\mathrm{NHOC}$, and viscosity can be feasibly estimated based on the $\mathrm{H} / \mathrm{C}$ molar ratio and $M$. This review provided an in-depth understanding of the composition-property relationship, which is meaningful to the evaluation and improvement of fuel properties.

All these established correlations of fuel composition and property are needed to define and determine fuel chemical compositions by analysis approaches, such as ${ }^{13} \mathrm{C}$ NMR, IR, GC, GC-MS, and GC $\times$ GC-MS, which show high accuracy in determining the fuel composition. Based on detailed composition, the correlations and predictions of hydrocarbon properties have meaningful implications on the development of aviation fuels. However, these predictions are significantly dependent on the analysis methods and correlation models, and certain limitations in the fuel composition determination and practical applications are still inevitable. Hence, further investigations for the detection of fuel chemical composition and the development of prediction methods need to be focused on to continuously improve the prediction accuracy.

Acknowledgements This work was supported by the Scientific Research Projects of the Ministry of Education of China (6141A02033522) and the National Natural Science Foundation of China (No. 21978200). 
Open Access This article is licensed under a Creative Commons Attribution 4.0 International License, which permits use, sharing, adaptation, distribution and reproduction in any medium or format, as long as you give appropriate credit to the original author(s) and the source, provide a link to the Creative Commons licence, and indicate if changes were made. The images or other third party material in this article are included in the article's Creative Commons licence, unless indicated otherwise in a credit line to the material. If material is not included in the article's Creative Commons licence and your intended use is not permitted by statutory regulation or exceeds the permitted use, you will need to obtain permission directly from the copyright holder. To view a copy of this licence, visit http://creativecommons.org/licenses/by/4.0/.

\section{References}

1. Braun-Unkhoff M, Kathrotia T, Rauch B et al (2016) About the interaction between composition and performance of alternative jet fuels. CEAS Aeronaut J 7(1):83-94

2. Billingsley M, Edwards T, Shafer LM et al (2010) Extent and impacts of hydrocarbon fuel compositional variability for aerospace propulsion systems. In: Proceedings of the 46th AIAA/ ASME/SAE/ASEE Joint Propulsion Conference \& Exhibit. Tennessee, USA: 6824

3. Vozka P, Kilaz G (2020) A review of aviation turbine fuel chemical composition-property relations. Fuel 268:117391

4. Elmalik EE, Raza B, Warrag S et al (2014) Role of hydrocarbon building blocks on gas-to-liquid derived synthetic jet fuel characteristics. Ind Eng Chem Res 53(5):1856-1865

5. Yang J, Xin Z, He QS et al (2019) An overview on performance characteristics of bio-jet fuels. Fuel 237:916-936

6. Luning Prak DJ, Romanczyk M, Wehde KE et al (2017) Analysis of catalytic hydrothermal conversion jet fuel and surrogate mixture formulation: components, properties, and combustion. Energy Fuels 31(12):13802-13814

7. Blakey S, Rye L, Wilson CW (2011) Aviation gas turbine alternative fuels: a review. Proc Combust Inst 33(2):2863-2885

8. Moses CA, Roets PNJ (2009) Properties, characteristics, and combustion performance of sasol fully synthetic jet fuel. J Eng Gas Turbines Power 10(1115/1):3028234

9. ASTM D7566-18 (2018) Standard specification for aviation turbine fuel containing synthesized hydrocarbons. ASTM International, Pennsylvania

10. ASTM D1655-18 (2018) Standard specification for aviation turbine fuels. ASTM International, Pennsylvania

11. Dukek WG (2011) Jet fuels. In: Kirk-Othmer Encyclopedia of Chemical Technology: Wiley, Hoboken, pp 1-31

12. Saldana DA, Starck L, Mougin P et al (2012) Prediction of density and viscosity of biofuel compounds using machine learning methods. Energy Fuels 26(4):2416-2426

13. Chi H, Li GQ, Guo YS et al (2013) Excess molar volume along with viscosity, flash point, and refractive index for binary mixtures of cis-decalin or trans-decalin with C9 to C11 n-alkanes. J Chem Eng Data 58(8):2224-2232

14. de Lorenzi L, Fermeglia M, Torriano G (1994) Densities and viscosities of 1,1,1-trichloroethane + paraffins and + cycloparaffins at 298.15 K. J Chem Eng Data 39(3):483-487

15. Geist JM, Cannon MR (1946) Viscosities of pure hydrocarbons. Ind Eng Chem Anal Ed 18(10):611-613

16. Jia TH, Gong S, Pan L et al (2020) Impact of deep hydrogenation on jet fuel oxidation and deposition. Fuel 264:116843

17. Chevalier JLE, Petrino PJ, Gaston-Bonhomme YH (1990) Viscosity and density of some aliphatic, cyclic, and aromatic hydrocarbons binary liquid mixtures. J Chem Eng Data 35(2):206-212

18. Edwards T, Maurice LQ (2001) Surrogate mixtures to represent complex aviation and rocket fuels. J Propuls Power 17(2):461-466

19. Al-Nuaimi IA, Bohra M, Selam M et al (2016) Optimization of the aromatic/paraffinic composition of synthetic jet fuels. Chem Eng Technol 39(12):2217-2228

20. Holley AT, Dong Y, Andac MG et al (2007) Ignition and extinction of non-premixed flames of single-component liquid hydrocarbons, jet fuels, and their surrogates. Proc Combust Inst 31(1):1205-1213

21. Nakakita K, Akihama K, Weissman W et al (2005) Effect of the hydrocarbon molecular structure in diesel fuel on the incylinder soot formation and exhaust emissions. Int J Engine Res 6(3):187-205

22. Zhang C, Hui X, Lin YZ et al (2016) Recent development in studies of alternative jet fuel combustion: progress, challenges, and opportunities. Renew Sustain Energy Rev 54:120-138

23. Wu ZY, Mao YB, Raza M et al (2019) Surrogate fuels for RP-3 kerosene formulated by emulating molecular structures, functional groups, physical and chemical properties. Combust Flame 208:388-401

24. Edwards T (2002) "Kerosene" fuels for aerospace propulsioncomposition and properties. In: Proceedings of the 38th AIAA/ ASME/SAE/ASEE Joint Propulsion Conference and Exhibit, Indianapolis, Indiana, USA

25. Zuber K, Bartl P (1989) Quality control of aviation fuels. 1. Automatic simulated distillation and calculation of the vapour pressure of JP-4 aviation fuel (AVTAG) using capillary gas chromatography. Fuel 68(5):659-663

26. Burger JL, Bruno TJ (2012) Application of the advanced distillation curve method to the variability of jet fuels. Energy Fuels 26(6):3661-3671

27. Bowden JN, Westbrook SR, LePera ME (1988) A survey of JP-8 and JP-5 properties. DTIC Document (Interim Report BFLRF No. 253). www.dtic.mil/dtic/tr/fulltext/u2/a2077 21.pdf. Accessed 24 May 2018

28. Lovestead TM, Bruno TJ (2009) A comparison of the hypersonic vehicle fuel JP-7 to the rocket propellants RP-1 and RP-2 with the advanced distillation curve method. Energy Fuels 23(7):3637-3644

29. Outcalt S, Laesecke A, Freund MB (2009) Density and speed of sound measurements of jet A and S-8 aviation turbine fuels. Energy Fuels 23(3):1626-1633

30. Lei Z, Lu CB, An GJ et al (2014) Comparative study on combustion and explosion characteristics of high flash point jet fuel. Procedia Eng 84:377-383

31. Irvine S, Schoettmer A, Bates R et al (2004) History of sulfur content effects on the thermal stability of RP-1 under heated conditions. 40th AIAA/ASME/SAE/ASEE Joint Propulsion Conference and Exhibit, Fort Lauderdale, Florida, USA:3879

32. Zhang XW, Pan L, Wang L et al (2018) Review on synthesis and properties of high-energy-density liquid fuels: hydrocarbons, nanofluids and energetic ionic liquids. Chem Eng Sci 180:95-125

33. Chung HS, Chen CSH, Kremer RA et al (1999) Recent developments in high-energy density liquid hydrocarbon fuels. Energy Fuels 13(3):641-649

34. Burdette GW, Lander HR, McCoy JR (1978) High-energy fuels for cruise missiles. J Energy 2(5):289-292

35. Pan L, Xie JJ, Nie GK et al (2020) Zeolite catalytic synthesis of high-performance jet-fuel-range spiro-fuel by one-pot Mannich-Diels-Alder reaction. AIChE J 66(1):e16789. https://doi. org/10.1002/aic.16789 
36. Xie JJ, Zhang XW, Pan L et al (2017) Renewable high-density spiro-fuels from lignocellulose-derived cyclic ketones. Chem Commun 53(74):10303-10305

37. von R Schleyer P, (1957) A simple preparation of adamantane. J Am Chem Soc 79(12):3292

38. Fort RC, Schleyer PR (1964) Adamantane: consequences of the diamondoid structure. Chem Rev 64(3):277-300

39. Schwertfeger H, Fokin A, Schreiner P (2008) Diamonds are a chemist's best friend: diamondoid chemistry beyond adamantane. Angew Chem Int Ed 47(6):1022-1036

40. Marchand AP (2003) CHEMISTRY: diamondoid hydrocarbons-delving into nature's bounty. Science 299(5603):52-53

41. Dahl JE (2003) Isolation and structure of higher diamondoids, nanometer-sized diamond molecules. Science 299(5603):96-99

42. Bren VA, Dubonosov AD, Minkin VI et al (1991) Norbornadiene-quadricyclane: an effective molecular system for the storage of solar energy. Russ Chem Rev 60(5):451-469

43. Bach RD, Schilke IL, Schlegel HB (1996) The energetics of valence isomerization in the norbornadiene-quadricyclane system. J Org Chem 61(14):4845-4847

44. Dubonosov AD, Bren VA, Chernoivanov VA (2002) Norbornadiene-quadricyclane as an abiotic system for the storage of solar energy. Russ Chem Rev 71(11):917-927

45. Pan L, Feng R, Peng H et al (2014) A solar-energy-derived strained hydrocarbon as an energetic hypergolic fuel. RSC Adv 4(92):50998-51001

46. Simmons HE, Smith RD (1958) A new synthesis of cyclopropanes from olefins. J Am Chem Soc 80(19):5323-5324

47. Simmons HE, Smith RD (1959) A new synthesis of cyclopropanes 1. J Am Chem Soc 81(16):4256-4264

48. Oh CH, Park DI, Ryu JH et al (2007) Syntheses and characterization of cyclopropane-fused hydrocarbons as new high energetic materials. Bull Korean Chem Soc 28(2):322-324

49. Shelley MD, El-Halwagi MM (2000) Component-less design of recovery and allocation systems: a functionality-based clustering approach. Comput Chem Eng 24(9-10):2081-2091

50. Cookson DJ, Lloyd CP, Smith BE (1987) Investigation of the chemical basis of kerosene (jet fuel) specification properties. Energy Fuels 1(5):438-447

51. Cookson DJ, Lloyd CP, Smith BE (1988) Investigation of the chemical basis of diesel fuel properties. Energy Fuels 2(6):854-860

52. Cookson DJ, Smith BE (1990) Calculation of jet and diesel fuel properties using carbon-13 NMR spectroscopy. Energy Fuels $4(2): 152-156$

53. Cookson DJ, Iliopoulos P, Smith BE (1995) Composition-property relations for jet and diesel fuels of variable boiling range. Fuel 74(1):70-78

54. Liu GZ, Wang L, Qu HJ et al (2007) Artificial neural network approaches on composition-property relationships of jet fuels based on GC-MS. Fuel 86(16):2551-2559

55. Shi XP, Li HJ, Song ZY et al (2017) Quantitative compositionproperty relationship of aviation hydrocarbon fuel based on comprehensive two-dimensional gas chromatography with mass spectrometry and flame ionization detector. Fuel 200:395-406

56. Morris RE, Hammond MH, Cramer JA et al (2009) Rapid fuel quality surveillance through chemometric modeling of nearinfrared spectra. Energy Fuels 23(3):1610-1618

57. Cramer JA, Morris RE, Rose-Pehrsson SL (2010) Use of genetic algorithms to improve partial least squares fuel property and synthetic fuel modeling from near-infrared spectra. Energy Fuels 24(10):5560-5572

58. Scheuermann SS, Forster S, Eibl S (2017) In-depth interpretation of mid-infrared spectra of various synthetic fuels for the chemometric prediction of aviation fuel blend properties. Energy Fuels 31(3):2934-2943
59. Gülüm M, Bilgin A (2015) Density, flash point and heating value variations of corn oil biodiesel-diesel fuel blends. Fuel Process Technol 134:456-464

60. Yue L, Li GQ, He GJ et al (2016) Impacts of hydrogen to carbon ratio $(\mathrm{H} / \mathrm{C})$ on fundamental properties and supercritical cracking performance of hydrocarbon fuels. Chem Eng J 283:1216-1223

61. Chen XY, Gao JJ, Lu YZ et al (2015) Acylation desulfurization of heavy cracking oil as a supplementary oil upgrading pathway. Fuel Process Technol 130:7-11

62. Annamalai K, Sweeten JM, Ramalingam SC (1987) Technical notes: estimation of gross heating values of biomass fuels. Trans ASAE 30(4):1205-1208

63. Albahri TA (2013) Method for predicting the standard net heat of combustion for pure hydrocarbons from their molecular structure. Energy Convers Manag 76:1143-1149

64. Blakey S, Wilson CW, Farmery M et al (2011) Fuel effects on range versus payload for modern jet aircraft. Aeronaut $\mathrm{J}$ 115(1172):627-634

65. Chuck CJ, Donnelly J (2014) The compatibility of potential bioderived fuels with Jet A-1 aviation kerosene. Appl Energy 118:83-91

66. Rothberg S, Jessup RS (1951) Net heat of combustion of AN-F58 aircraft fuels. Ind Eng Chem 43(4):981-985

67. Antoine AC (1980) Use of petroleum-based correlations and estimation methods for synthetic fuels. NASA Technical Memorandum 81533. https://ntrs.nasa.gov/citations/ 19800019008. Accessed 1 June 1980

68. Solash J, Hazlett R, Hall J et al (1978) Relation between fuel properties and chemical composition. 1. Jet fuels from coal, oil shale and tar sands. Fuel 57(9):521-528

69. Nie GK, Zhang XW, Pan L et al (2017) Hydrogenated intramolecular cyclization of diphenylmethane derivatives for synthesizing high-density biofuel. Chem Eng Sci 173:91-97

70. Savos'kin MV, Kapkan LM, Vaiman GE et al (2007) New approaches to the development of high-performance hydrocarbon propellants. Russ J Appl Chem 80(1):31-37

71. ASTM D3338/D3338M-20 (2020) Standard test method for estimation of net heat of combustion of aviation fuels. ASTM International, Pennsylvania. https://doi.org/10.1520/d3338

72. ASTM D4529-17 (2017) Standard test method for estimation of net heat of combustion of aviation fuels. ASTM International, Pennsylvania

73. Fodor GE, Kohl KB (1993) Analysis of middle distillate fuels by midband infrared spectroscopy. Energy Fuels 7(5):598-601

74. Xie JJ, Zhang XW, Liu YK et al (2019) Synthesis of high-density liquid fuel via Diels-Alder reaction of dicyclopentadiene and lignocellulose-derived 2-methylfuran. Catal Today 319:139-144

75. Wang L, Zhang XW, Zou JJ et al (2009) Acid-catalyzed isomerization of tetrahydrotricyclopentadiene: synthesis of high-energydensity liquid fuel. Energy Fuels 23(5):2383-2388

76. Lamprecht D (2007) Fischer-Tropsch fuel for use by the US military as battlefield-use fuel of the future. Energy Fuels 21(3):1448-1453

77. Knothe G, Steidley KR (2005) Kinematic viscosity of biodiesel fuel components and related compounds. Influence of compound structure and comparison to petrodiesel fuel components. Fuel 84(9):1059-1065

78. Balster LM, Corporan E, DeWitt MJ et al (2008) Development of an advanced, thermally stable, coal-based jet fuel. Fuel Process Technol 89(4):364-378

79. Cai GQ, Liu ZF, Zhang LZ et al (2018) Quantitative structureproperty relationship model for hydrocarbon liquid viscosity prediction. Energy Fuels 32(3):3290-3298

80. Jeihouni Y, Pischinger S, Ruhkamp L et al (2011) Relationship between fuel properties and sensitivity analysis of non-aromatic 
and aromatic fuels used in a single cylinder heavy duty diesel engine. SAE Technical Paper: 2011-01-0333, Warrendale, PA, USA

81. Dixon JA, Clark SGII (1959) Physical properties of high molecular weight alkylbenzenes and alkylcyclohexanes. J Chem Eng Data 4(1):94-96

82. Grunberg L, Nissan AH (1949) Mixture law for viscosity. Nature 164(4175):799-800

83. Allen CAW, Watts KC, Ackman RG et al (1999) Predicting the viscosity of biodiesel fuels from their fatty acid ester composition. Fuel 78(11):1319-1326

84. Yuan W, Hansen AC, Zhang Q (2009) Predicting the temperature dependent viscosity of biodiesel fuels. Fuel 88(6):1120-1126

85. ASTM D2386-19 (2019) Standard test method for freezing point of aviation fuels. ASTM International, Pennsylvania

86. Affens WA, Hall JM, Holt S et al (1984) Effect of composition on freezing points of model hydrocarbon fuels. Fuel 63(4):543-547

87. Duong LH, Fujita O, Reksowardojo IK et al (2016) Experimental investigation of the effects of cycloparaffins and aromatics on the sooting tendency and the freezing point of soap-derived biokerosene and normal paraffins. Fuel 185:855-862

88. Coetzer RLJ, Joubert TS, Viljoen CL et al (2018) Response surface models for synthetic jet fuel properties. Appl Petrochem Res 8(1):39-53

89. Vozka P, Šimáček P, Kilaz G (2018) Impact of HEFA feedstocks on fuel composition and properties in blends with jet A. Energy Fuels 32(11):11595-11606

90. Robota HJ, Alger JC, Shafer L (2013) Converting algal triglycerides to diesel and HEFA jet fuel fractions. Energy Fuels 27(2):985-996

91. Corporan E, Edwards T, Shafer L et al (2011) Chemical, thermal stability, seal swell, and emissions studies of alternative jet fuels. Energy Fuels 25(3):955-966

92. Han PJ, Nie GK, Xie JJ et al (2017) Synthesis of high-density biofuel with excellent low-temperature properties from lignocellulose-derived feedstock. Fuel Process Technol 163:45-50

93. Nie GK, Zhang XW, Pan L et al (2018) One-pot production of branched decalins as high-density jet fuel from monocyclic alkanes and alcohols. Chem Eng Sci 180:64-69

94. Hong TD, Soerawidjaja TH, Reksowardojo IK et al (2013) A study on developing aviation biofuel for the tropics: production process: experimental and theoretical evaluation of their blends with fossil kerosene. Chem Eng Process: Process Intensif 74:124-130

95. AlMulla HA, Albahri TA (2017) Predicting the properties of petroleum blends. Petrol Sci Technol 35(8):775-782

96. Aleme HG, Barbeira PJS (2012) Determination of flash point and cetane index in diesel using distillation curves and multivariate calibration. Fuel 102:129-134

97. Phoon LY, Mustaffa AA, Hashim H et al (2014) A review of flash point prediction models for flammable liquid mixtures. Ind Eng Chem Res 53(32):12553-12565

98. Poor HM, Sadrameli SM (2017) Calculation and prediction of binary mixture flash point using correlative and predictive local composition models. Fluid Phase Equilib 440:95-102

99. Affens WA, McLaren GW (1972) Flammability properties of hydrocarbon solutions in air. J Chem Eng Data 17(4):482-488

100. Shepherd JE, Nuyt CD, Lee JJ et al (2000) Flash point and chemical composition of aviation kerosene (Jet A). Explosion Dynamics Laboratory Report FM99-4, California, USA. https://authors.library.caltech.edu/25832/. Accessed 26 May 2000

101. Saldana DA, Starck L, Mougin P et al (2013) Prediction of flash points for fuel mixtures using machine learning and a novel equation. Energy Fuels 27(7):3811-3820
102. Ding C, He YP, Yin JS et al (2015) Study on the pressure dependence of boiling point, flashpoint, and lower flammability limit at low ambient pressure. Ind Eng Chem Res 54(6):1899-1907

103. Albahri TA (2003) Flammability characteristics of pure hydrocarbons. Chem Eng Sci 58(16):3629-3641

104. Katritzky AR, Petrukhin R, Jain R et al (2001) QSPR analysis of flash points. J Chem Inf Comput Sci 41(6):1521-1530

105. Wickey RO, Chittenden DH (1963) Flash points of blends correlated. Hydrocarb Process 42(6):157-158

106. Vidal M, Rogers WJ, Holste JC et al (2004) A review of estimation methods for flash points and flammability limits. Proc Saf Prog 23(1):47-55

107. Liu XS, Liu ZY (2010) Research progress on flash point prediction. J Chem Eng Data 55(9):2943-2950

108. Song CS, Eser S, Schobert HH et al (1993) Pyrolytic degradation studies of a coal-derived and a petroleum-derived aviation jet fuel. Energy Fuels 7(2):234-243

109. Ben Amara A, Kaoubi S, Starck L (2016) Toward an optimal formulation of alternative jet fuels: enhanced oxidation and thermal stability by the addition of cyclic molecules. Fuel 173:98-105

110. DeWitt MJ, West Z, Zabarnick S et al (2014) Effect of aromatics on the thermal-oxidative stability of synthetic paraffinic kerosene. Energy Fuels 28(6):3696-3703

111. van der Westhuizen R, Ajam M, de Coning P et al (2011) Comprehensive two-dimensional gas chromatography for the analysis of synthetic and crude-derived jet fuels. J Chromatogr A 1218(28):4478-4486

112. Adams RK, Zabarnick S, West ZJ et al (2013) Chemical analysis of jet fuel polar, heteroatomic species via high-performance liquid chromatography with electrospray ionization-mass spectrometric detection. Energy Fuels 27(5):2390-2398

113. Beaver B, Gao L, Burgess-Clifford C et al (2005) On the mechanisms of formation of thermal oxidative deposits in jet fuels. Are unified mechanisms possible for both storage and thermal oxidative deposit formation for middle distillate fuels? Energy Fuels 19(4):1574-1579

114. Klettlinger J, Rich R, Yen C et al (2011) Thermal stability testing of Fischer-Tropsch fuel and various blends with Jet A, as well as aromatic blend additives. In: Proceedings of the IEEE 2011 Energy Tech, May 25-26, 2011. Cleveland, OH

115. Pullen J, Saeed K (2012) An overview of biodiesel oxidation stability. Renew Sustain Energy Rev 16(8):5924-5950

116. Berkhous SK (2007) Thermal oxidative stability of coal-based JP-900 jet fuel: impact on selected physical properties. The Pennsylvania State University, Pennsylvania,

117. Knothe G (2007) Some aspects of biodiesel oxidative stability. Fuel Process Technol 88(7):669-677

118. Chatelain K, Nicolle A, Ben Amara A et al (2016) Wide range experimental and kinetic modeling study of chain length impact on n-alkanes autoxidation. Energy Fuels. https://doi.org/10.1021/ acs.energyfuels. $5 \mathrm{~b} 02470$

119. Chatelain K, Nicolle A, Ben Amara A et al (2018) Structurereactivity relationships in fuel stability: experimental and kinetic modeling study of isoparaffin autoxidation. Energy Fuels 32(9):9415-9426

120. Larsen RG, Thorpe RE, Armfield FA (1942) Oxidation characteristics of pure hydrocarbons. Ind Eng Chem 34(2):183-193

121. Rawson PM, Stansfield CA, Webster RL et al (2015) The oxidative stability of synthetic fuels and fuel blends with monoaromatic blending components. Fuel 161:97-104 


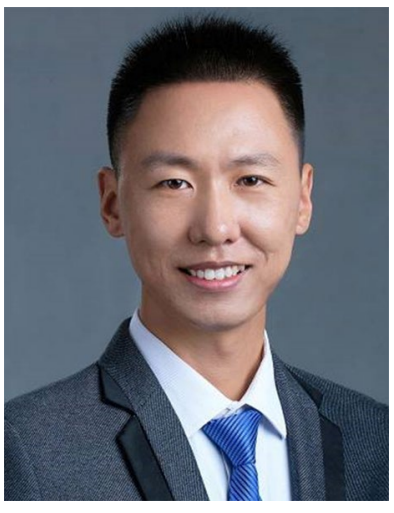

Lun Pan received his B.S. degree and Ph.D. from the School of Chemical Engineering and Technology, Tianjin University, China, in 2009 and 2014, respectively, and was a visiting scholar in Georgia Institute of Technology from 2016 to 2017. Now he is an Associate Professor in Tianjin University, and his research interests mainly focus on the fuel processing technology and fuel science. He has authored/coauthored 10 patents and more than 50 papers, including Nature Commun., JACS,

AIChE J., CES, Adv. Mater., Nano Energy, ACS Nano, AEM, ACS Catal., Adv. Sci., and Appl. Catal. B, etc.

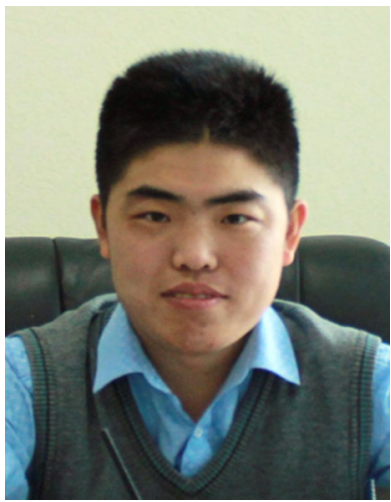

Yunming Fang graduated as Ph.D. at the Department of Chemical Engineering of Dalian University of Technology (2008). He was appointed Assistant/Associate Professor at Qingdao Institute of Bioenergy and Bioprocess Technology, Chinese Academy of Sciences. He joined the Department of Chemical Engineering of Beijing University of Chemical Technology as full Professor since 2013. His main research area is bioenergy and related catalytic engineering. He has authored/coauthored

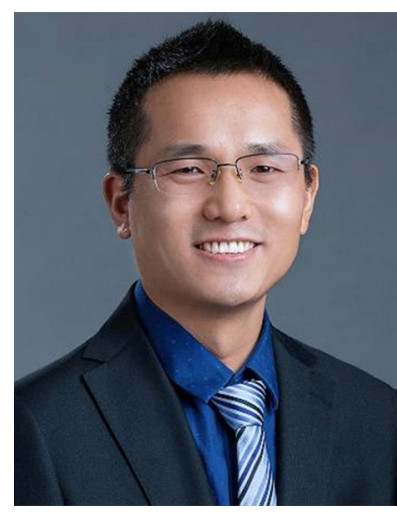

Ji-Jun Zou is the Head of Department of Chemical Technology and Chair Professor in Tianjin University, China. He received his B.S., M.S. and Ph.D. degrees in Chemical Engineering from Tianjin University in 2000, 2002 and 2005 , respectively. He was promoted as full professor of Chemical Engineering in 2013, and became Deputy Director of Key Laboratory of Advanced Fuel and Chemical Propellant of Ministry of Education in 2012. Prof. Zou has been devoted to the investigation and development of aerospace fuels for more than 10 years. He has authored/coauthored more than 150 papers and 30 patents. He has received several awards including Technological Leading Scholar of 10000 Talent project (2017), Changjiang Young Scholar by the Ministry of Education (2016), National Excellent Young Scientist by the National Natural Science Foundation of China (2012), National Excellent Doctoral Dissertation by the Ministry of Education (2008) and Peiyang Distinguished Young Scholar by Tianjin University (2009). He is also an Associate Editor of RSC Advances.

more than 60 papers and 15 patents. 